\title{
Animal models of nicotine exposure: relevance to second-hand smoking, electronic cigarette use, and compulsive smoking
}

\author{
Ami Cohen and Olivier George* \\ Committee on the Neurobiology of Addictive Disorders, The Scripps Research Institute, La Jolla, CA, USA
}

\author{
Edited by: \\ Nicholas W. Gilpin, Louisiana State \\ University Health Sciences \\ Center-New Orleans, USA

\section{Reviewed by:} \\ Angelo Giovanni Icro Maremmani, \\ University of Pisa, Italy \\ M. I. Damaj, Virginia Commonwealth \\ University, USA \\ Laura Elena O'Dell, The University of \\ Texas at EI Paso, USA \\ *Correspondence: \\ Olivier George, Committee on the \\ Neurobiology of Addictive Disorders, \\ The Scripps Research Institute, 10550 \\ North Torrey Pines Road, SP30-2400, \\ La Jolla, CA 92037, USA \\ e-mail: ogeorge@scripps.edu
}

\begin{abstract}
Much evidence indicates that individuals use tobacco primarily to experience the psychopharmacological properties of nicotine and that a large proportion of smokers eventually become dependent on nicotine. In humans, nicotine acutely produces positive reinforcing effects, including mild euphoria, whereas a nicotine abstinence syndrome with both somatic and affective components is observed after chronic nicotine exposure. Animal models of nicotine self-administration and chronic exposure to nicotine have been critical in unveiling the neurobiological substrates that mediate the acute reinforcing effects of nicotine and emergence of a withdrawal syndrome during abstinence. However, important aspects of the transition from nicotine abuse to nicotine dependence, such as the emergence of increased motivation and compulsive nicotine intake following repeated exposure to the drug, have only recently begun to be modeled in animals. Thus, the neurobiological mechanisms that are involved in these important aspects of nicotine addiction remain largely unknown. In this review, we describe the different animal models available to date and discuss recent advances in animal models of nicotine exposure and nicotine dependence. This review demonstrates that novel animal models of nicotine vapor exposure and escalation of nicotine intake provide a unique opportunity to investigate the neurobiological effects of second-hand nicotine exposure, electronic cigarette use, and the mechanisms that underlie the transition from nicotine use to compulsive nicotine intake.
\end{abstract}

Keywords: addiction, tobacco, self-administration, vapor, dependence, escalation, abstinence, withdrawal

\section{INTRODUCTION}

Studies on the neurobiological substrates of tobacco addiction largely depend on the availability of suitable animal models. In this review, we first describe the features of tobacco smoking and nicotine abuse and dependence in humans. We then discuss the limits and advantages of the most used animal models of nicotine use and dependence and novel animal models of escalated nicotine intake and exposure to nicotine vapor. The last section discusses how these different animal models can be used to investigate the neurobiological mechanisms that mediate nicotine reinforcement and dependence.

\section{FEATURES OF TOBACCO SMOKING, NICOTINE ABUSE, AND DEPENDENCE IN HUMANS}

Tobacco use is the leading cause of preventable disease and premature death, leading to 440,000 deaths annually in the United States alone (Fellows et al., 2002). According to a recent review (Giovino et al., 2012), 24\% of the United States population older than 15 years of age are cigarette smokers, and $1.8 \%$ are smokeless tobacco users. Cigarette smoking appears to be more central to the epidemiology of nicotine addiction compared with smokeless tobacco abuse. However, chewing tobacco, dry snuff, and moist snuff are a concern in certain countries (Bhattacharyya, 2012; Giovino et al., 2012). The rapid growth of electronic cigarette use worldwide (Caponnetto et al., 2012) is also an important health concern that requires the development of novel animal models of exposure to nicotine vapor.

\section{ACUTE EFFECTS OF SMOKING}

The primary psychoactive ingredient responsible for tobacco use is nicotine (Cummings and Mahoney, 2006), although tobacco smoke also contains more than 4,000 additional chemicals, many of which have psychoactive properties or may act in concert with nicotine to contribute to smoking dependence (Clemens et al., 2009; Hoffman and Evans, 2013). Cigarettes typically contain 10$14 \mathrm{mg}$ of nicotine (Kozlowski et al., 1998), of which $1-1.5 \mathrm{mg}$ is absorbed systemically in the lungs through inhalation (Armitage et al., 1975; Benowitz and Jacob, 1984). Nicotine rapidly enters the pulmonary venous circulation, reaches the brain within 10-20 s, and readily diffuses into brain tissue where it binds to nicotine acetylcholine receptors (nAChRs; Benowitz et al., 1988). The rate of absorption of smokeless tobacco products, with the exception of electronic cigarettes, is considerably slower (30 min to reach maximum blood levels), accounting for a lower abuse potential for these products (Benowitz et al., 1988). Acutely, cigarette smoking is reported to induce positive reinforcing effects, including mild euphoria, heightened arousal, reduced appetite, and reduced stress, anxiety, and pain (Pomerleau et al., 1984; Pomerleau and Pomerleau, 1992; Stolerman and Jarvis, 1995). However, the specific role for nicotine in these reinforcing effects is still unclear because of the 
difficulties performing intravenous nicotine self-administration in humans. However, smokers who self-administer nicotine report an overall profile of rewarding sensations, including mild euphoria, increased comfort, "drug liking," and reduced negative mood and pain sensation, accompanied by negative effects, such as tension and jitteriness (Henningfield and Goldberg, 1983; Perkins et al., 1994; Harvey et al., 2004; Sofuoglu et al., 2008; Rose et al., 2010). Thus, nicotine itself can serve as an effective reinforcer, at least among experienced smokers. However, the mixed subjective reports, early difficulties obtaining reliable intravenous nicotine self-administration in animals, and direct comparisons in animal models suggest that the reinforcing efficacy of nicotine is lower than other drugs of abuse (Risner and Goldberg, 1983; Manzardo et al., 2002; Le Foll and Goldberg, 2009). Non-nicotinic aspects of tobacco smoke, such as its other constituents (e.g., acetaldehyde, nornicotine, and harman) and sensory stimulation could substantially contribute to its abuse and addictive potential (Belluzzi et al., 2005; Rose, 2006; Rose et al., 2010; Kapelewski et al., 2011).

\section{TOBACCO DEPENDENCE}

\section{Patterns of smoking among dependent smokers}

Dependent smokers maintain relatively stable nicotine blood levels during waking hours (Benowitz and Jacob, 1984), with plasma levels ranging between 20 and $50 \mathrm{ng} / \mathrm{ml}$. To maintain these relatively constant nicotine levels, smokers efficiently regulate the rate and intensity of cigarette smoking (Ashton and Watson, 1970; Benowitz, 1986). For example, smokers will compensate for reduced nicotine content when smoking cigarettes with lower nicotine yield than their usual brand (Russell et al., 1980; Maron and Fortmann, 1987).

\section{Nicotine withdrawal and the escalation of nicotine intake}

Discontinuation of smoking, even for only several hours, leads to withdrawal symptoms that peak within 1 week and may persist for up to 6 months (Hughes et al., 1991; Hughes, 2007; Markou, 2008). Nicotine withdrawal includes both somatic symptoms, such as bradycardia, gastrointestinal disturbances, and, increased appetite, and affective symptoms, such as nicotine craving, heightened anxiety, hyperalgesia, depressed mood, and irritability (Pomerleau et al., 1984; Hughes et al., 1991; Zaniewska et al., 2009; Rose et al., 2010). Converging evidence shows that avoidance of the affective symptoms of nicotine withdrawal, rather than somatic symptoms, plays a central role in the maintenance of nicotine dependence (Koob et al., 1993). It has been hypothesized that during the transition to dependence, the motivation to take drugs is caused by a shift from the positive reinforcing properties of the drug to its ability to attenuate the negative effects of abstinence. Thus, the negative affective states associated with abstinence potentiate the incentive value of nicotine to promote the escalation of compulsive drug intake through negative reinforcement mechanisms (Solomon and Corbit, 1973; Koob and Le Moal, 2001; Koob, 2010).

\section{Adolescence and the escalation of tobacco smoking}

Tobacco smoking typically begins in adolescence, with $14 \%$ of 15 year-olds and $22 \%$ of 17 -year-olds reporting cigarette smoking (Substance Abuse and Mental Health Services Administration, 2003). Prospective studies report that $\sim 30-50 \%$ of adolescents and young adults who had initiated non-daily smoking showed an escalation in daily smoking within $4-5$ years (U.S. Department of Health and Human Services, 1994, 2012; Tucker et al., 2003). For example, one 4 -year prospective study reports that $53 \%$ of sixth-graders who experimented with smoking experience dependence symptoms, and $40 \%$ experience escalation to daily smoking (Doubeni et al., 2010). Some adolescents and young adults who experiment with smoking will eventually quit or remain light smokers (one to five cigarettes/day) or intermittent smokers ("chippers"; Shiffman, 1989; Shiffman et al., 1994), a subpopulation that encompasses up to $25-33 \%$ of all smokers (Coggins et al., 2009).

Various psychosocial factors, such as peer smoking and parenting style, have been suggested to contribute to the escalated smoking behavior of certain adolescents (Robinson et al., 2003; Kim et al., 2009; Dal Cin et al., 2012). Interestingly, studies suggest that, contrary to the common perception, symptoms of nicotine dependence, most commonly craving for tobacco and withdrawal symptoms (Gervais et al., 2007; Doubeni et al., 2010; Zhan et al., 2012), can develop at very early stages of initial intermittent smoking, even with as few as two cigarettes per week (DiFranza et al., 2002). According to Zhan et al. (2012), 20\% of adolescents who smoke fewer than 100 cigarettes in their lifetime report experiencing "smoking to relieve restlessness" and "irritability." As expected, the early appearance of such symptoms of nicotine dependence predicts future escalation to daily chronic smoking (DiFranza et al., 2002, 2007; Dierker and Mermelstein, 2010; Doubeni et al., 2010). In contrast, people who engage in non-daily smoking without escalation ("chippers") have very few or no symptoms of dependence, and their smoking experience is primarily associated with positive rather than negative reinforcement (Coggins et al., 2009). Thus, intermittent tobacco use associated with withdrawal symptoms can promote the escalation of smoking behavior, which in turn accelerates the appearance of additional symptoms of dependence (Doubeni et al., 2010).

The importance of nicotine withdrawal as a negative reinforcer in the escalation of smoking is also suggested by the calming effects of nicotine when given after even a short period of abstinence, a primary reason given by both adults and adolescents for smoking (Dozois et al., 1995; Parrott, 1995). Although nicotine has anxiolytic properties under certain conditions (Pomerleau et al., 1984; Perkins and Grobe, 1992; Juliano and Brandon, 2002), it has also been argued that the calming effects of nicotine in dependent smokers represent the reversal of the negative affect induced by nicotine deprivation (Parrott, 1995, 1998, 2003). Thus, escalation may be more common among individuals with difficulties regulating negative affect, who are prone to develop withdrawal symptoms, and who have high expectancy of the calming effects of smoking (Heinz et al., 2010).

\section{SECOND-HAND SMOKE}

One generally overlooked factor that may contribute to the escalation of tobacco abuse, particularly among adolescents, is secondhand smoking. In the United States, it has been estimated that up to $60 \%$ of children are exposed to second-hand smoke (U.S. Department of Health and Human Services, 2006). Nicotine from moderate second-hand smoke exposure results in an increase in 
plasma nicotine concentration of approximately $0.2 \mathrm{ng} / \mathrm{ml}$ and to substantial brain $\alpha_{4} \beta_{2}^{*}$ nAChR occupancy (19\%) in both smokers and non-smokers compared with $0.87 \mathrm{ng} / \mathrm{ml}$ and $50 \% \alpha_{4} \beta_{2}^{*}$ $\mathrm{nAChR}$ occupancy from actively smoking one cigarette (Brody et al., 2006, 2011). Although second-hand smoking is clearly linked to serious illnesses among non-smokers (U.S. Department of Health and Human Services, 2006), including asthma, heart disease, sudden infant death syndrome, and cancer, it is currently unclear whether second-hand smoke can also contribute to the initiation and escalation of smoking. It is well documented that adolescents exposed to smoking by family members and peers are more likely to initiate and escalate smoking behavior (Brook et al., 2009; Leonardi-Bee et al., 2011; Wang et al., 2011). However, various psychological, psychosocial, and genetic factors may mediate this effect (Ajzen and Fishbein, 1980; O'Byrne et al., 2002; Audrain-McGovern et al., 2007). Nevertheless, escalated smoking can be observed in adolescent smokers with cotinine plasma levels comparable to levels of second-hand smoking in non-smokers (DiFranza et al., 2007). Moreover, adults and children who are non-smokers report symptoms of nicotine withdrawal after exposure to high levels of second-hand smoke (Okoli et al., 2007; Bélanger et al., 2008). Finally, prospective studies suggest that high levels of nicotine intake from second-hand smoking during childhood predict smoking behavior in teenage years, even when accounting for various social and environmental factors (Becklake et al., 2005). However, the controlled experimental conditions that are required to test the causal role of second-hand smoking in the escalation of smoking can only be employed in animal models and will be discussed below.

\section{ELECTRONIC CIGARETTES}

Electronic cigarettes deliver nicotine through the battery-powered vaporization of a nicotine/propylene-glycol solution. Electronic cigarettes (e-cigarettes) are thus generally less harmful than regular cigarettes because they deliver nicotine without the various toxic constituents of tobacco smoke (Cahn and Siegel, 2011; Etter and Bullen, 2011; O'Connor, 2012). According to a recent survey, 3.4\% of the total population, including $11.4 \%$ of current smokers, $2.0 \%$ of former smokers, and $0.8 \%$ of never-smokers, use e-cigarettes (Pearson et al., 2012). Most smokers claim to use e-cigarettes for smoking cessation/reduction, and their use appears to enhance the motivation to quit (Etter and Bullen, 2011; Wagener et al., 2012). Indeed, two surveys reported that most smokers who used ecigarettes decreased or completely quit smoking within 6 months (Polosa et al., 2011; Siegel et al., 2011). However, it is unclear the degree to which such reports coincide with the efficacy of ecigarettes as nicotine delivery devices. Vansickel and Eissenberg (2013) report that experienced users who were allowed to use their own customized e-cigarettes reach blood nicotine concentrations similar to those obtained by regular cigarettes. However, other studies report that nicotine delivery greatly varies between brands but is generally lower than that of regular cigarettes, with certain brands delivering nicotine doses that are too low to be detected (Bullen et al., 2010; Vansickel et al., 2010; Goniewicz et al., 2013). These studies report that e-cigarette use reduces craving and partially alleviated withdrawal symptoms despite the low to moderate blood nicotine levels. The effect of e-cigarette use on the brain stress and reward systems and vulnerability to become dependent or relapse is unknown and needs to be addressed using novel animal models. Another key question that needs to be investigated is the possible role of e-cigarettes as a gateway product to other drugs of abuse (Etter, 2012).

\section{ANIMAL MODELS OF NICOTINE ABUSE AND DEPENDENCE NON-CONTINGENT EXPOSURE TO NICOTINE}

Most research on the behavioral and biological effects of nicotine involved experimenter-administered nicotine, given by subcutaneous (s.c.) or intraperitoneal (i.p.) injections (see Figure 1). Non-contingent nicotine injections were instrumental in identifying the effects of acute and chronic exposure to nicotine on a wide variety of phenomena, including locomotor activity (Clarke and Kumar, 1983), anxiety-like behavior (Irvine et al., 1999; Cheeta et al., 2001), feeding behavior (Clarke and Kumar, 1984), pain (Sahley and Berntson, 1979), the development of tolerance to such effects (Collins et al., 1988), and the brain systems involved (Rosecrans and Meltzer, 1981; Clarke et al., 1988; Niijima et al., 2001).

\section{Conditioned place preference}

In this model of drug reward, animals are tested for the development of conditioned preferences for distinct drug-paired environments (Carr et al., 1989). Achieving nicotine-induced conditioned place preference (CPP) in rodents has proven to be challenging compared with other drugs of abuse, and findings have been inconsistent. Nicotine-induced CPP is observed in some studies (Fudala et al., 1985; Horan et al., 1997; Ashby et al., 2002; Le Foll and Goldberg, 2005) but not in others (Clarke and Fibiger, 1987; Acquas et al., 1989; Jorenby et al., 1990; Parker, 1992). Nicotine can also induce conditioned place aversion (CPA; Horan et al., 1997; Laviolette and van der Kooy, 2003). The ability to achieve nicotineinduced CPP is facilitated by the use of a "biased" place preference procedure (i.e., pairing the drug with the initially non-preferred compartment of the CPP apparatus; Le Foll and Goldberg, 2005). The reasons for the difficulty obtaining CPP are unclear and may be related to the weak rewarding properties of nicotine and very narrow dose-response curve.

\section{Dependence induction}

Termination of repeated nicotine injections in rodents results in behavioral and physiological states consistent with drug withdrawal (see review by Malin, 2001), such as heightened stress responses (Benwell and Balfour, 1979), the disruption of appetitive operant responding (Ford and Balster, 1976; Carroll et al., 1989), and weight gain (Grunberg et al., 1986; Levin et al., 1987). The induction of nicotine dependence by subcutaneous nicotine delivery via osmotic minipumps has gained popularity since its first introduction by Malin et al. (1992). In this method, dependence is induced by $\geq 6$ days of continuous subcutaneous nicotine infusion (commonly $\geq 3.16 \mathrm{mg} / \mathrm{kg}$ free base/day in rats and $\geq 12 \mathrm{mg} / \mathrm{kg} /$ day in mice). Withdrawal is subsequently induced by terminating the infusion (peaking within $18-22 \mathrm{~h}$; Malin et al., 1992) or precipitated by injecting nAChR antagonists, such as mecamylamine (Malin et al., 1992; Isola et al., 1999; Damaj, 2000; Malin, 2001). The symptoms of withdrawal 


\begin{tabular}{|c|c|c|c|c|c|c|}
\hline & \multirow[t]{2}{*}{$\begin{array}{l}\text { Acute non-contingent } \\
\text { injections }\end{array}$} & \multirow[t]{2}{*}{$\begin{array}{l}\text { Limited access } \\
\text { self-administration }\end{array}$} & \multicolumn{2}{|c|}{ Chronic non-contingent exposure } & \multicolumn{2}{|c|}{$\begin{array}{l}\text { Extended access } \\
\text { self-administration }\end{array}$} \\
\hline & & & Exposure & Withdrawal & Exposure & Withdrawal \\
\hline $\begin{array}{l}\text { ICSS } \\
\text { Brain reward } \\
\text { threshold }\end{array}$ & $\begin{array}{l}\boldsymbol{\downarrow}_{0.1-1 \mathrm{mg} / \mathrm{kg}(1,4,6,} \\
7,14) \\
\boldsymbol{\uparrow}>1 \mathrm{mg} / \mathrm{kg}(1)\end{array}$ & $\begin{array}{l}\boldsymbol{\psi}_{\mathrm{NSA}<2 \mathrm{~h} / \mathrm{d}} \\
(8,10,12)\end{array}$ & $\begin{array}{l}\boldsymbol{V}_{\text {minipump }(2,7)} \\
\overrightarrow{\text { smoke }}_{(15)}\end{array}$ & $\begin{array}{l}T_{\text {minipump }} \\
(3,5,7,8,11)\end{array}$ & $\begin{array}{l}\boldsymbol{\psi}_{\mathrm{NSA}: 2-} \\
12 \mathrm{~h} / \mathrm{d}(8,10,12)\end{array}$ & $\begin{array}{l}\boldsymbol{W}_{\mathrm{NSA}: 2-} \\
\text { 12h/day }(8,11, \\
12,13) \\
\boldsymbol{T}_{\mathrm{NSA}} \text { :22h/day } \\
(16)\end{array}$ \\
\hline Anxiety-like behavior & $\begin{array}{l}\boldsymbol{W}<0.1 \mathrm{mg} / \mathrm{kg} \text { s.c/i.p). } \\
\boldsymbol{\top}>0.1 \mathrm{mg} / \mathrm{kg} \\
(17-20)\end{array}$ & $\begin{array}{l}\uparrow_{N S A<2 h / d} \\
(19)\end{array}$ & $\begin{array}{l}\text { Tolerance to } \\
\text { anxiolytic and } \\
\text { anxiogenic effects } \\
(19,21)\end{array}$ & T(22, 23) & ? & ? \\
\hline $\begin{array}{l}\text { Conditioned place } \\
\text { preference/aversion }\end{array}$ & $\begin{array}{l}\text { CPP } 0.1-1.4 \mathrm{mg} / \mathrm{kg} \\
\text { CPA }>1.4 \mathrm{mg} / \mathrm{kg} \\
(24)\end{array}$ & $?$ & ? & $\begin{array}{l}\text { CPA } \\
(25-29)\end{array}$ & $?$ & ? \\
\hline Pain & $\underset{(30-32)}{\downarrow}$ & ? & $\begin{array}{l}\boldsymbol{W}_{\text {With Tolerance }} \\
(33,34) \\
\boldsymbol{N}(35)\end{array}$ & $\boldsymbol{T}_{(36-39)}$ & ? & ? \\
\hline
\end{tabular}

FIGURE 1 | Effects of acute/chronic non-contingent nicotine exposure, limited/extended access to nicotine self-administration (NSA), and withdrawal from chronic nicotine on measures of reward threshold (ICSS), anxiety-like behavior, and reward (CPP) or aversion (CPA). Note that the effect of withdrawal from chronic nicotine on the reward thresholds differed depending on the type of nicotine delivery. 1. Huston-Lyons and Kornetsky (1992), 2. Bozarth et al. (1998a), 3. Bozarth et al. (1998b), 4. Bespalov et al. (1999), 5. Watkins et al. (2000a), 6. Harrison et al. (2002), 7. Cryan et al. (2003), 8. Kenny and Markou (2005), 9. Kenny and Markou (2006), 10. Kenny et al. (2009), 11. Johnson et al.
(2008), 12. Paterson et al. (2008), 13. Bruijnzeel et al. (2009), 14. Spiller et al. (2009), 15. Yamada et al. (2010) 16. Harris et al. (2011); 17. Brioni et al. (1993); 18. Irvine et al. (1999), 19. Irvine et al. (2001), 20. Tucci et al. (2003); 21. Biala and Budzynska (2006), 22. Stoker et al. (2008), 23. Cippitelli et al. (2011), 24. Le Foll and Goldberg (2005), 25. Miyata et al. (2011), 26. Suzuki et al. (1996), 27. Shram et al. (2008), 28. Grieder et al. (2012), 29. Grieder et al. (2010), 30. Damaj et al. (1994), 31. Sahley and Berntson (1979), 32. Craft and Milholland (1998), 33. Yang et al. (1992), 34. Galeote et al. (2006), 35. Lough et al. (2007), 36. Grabus et al. (2005), 37. Jackson et al. (2008), 38. Schmidt et al. (2001), 39. Yang et al. (1992). are commonly divided into "somatic" signs that resemble opiate withdrawal (e.g., teeth-chattering, chewing, writhing, tremors, and body shakes; Malin et al., 1992). Although a well-accepted marker for nicotine dependence, these somatic withdrawal signs do not appear to be similar to those in humans or strongly predict drug use or relapse compared with affective symptoms (Koob and Le Moal, 2001; Hughes, 2007). Affective symptoms can be measured using CPA to nicotine withdrawal (Shram et al., 2008; Jackson et al., 2009), anxiety-like behavior (Wilmouth and Spear, 2006), and increased reward thresholds in the intracranial selfstimulation (ICSS) paradigm. The increased reward thresholds are interpreted as reflecting a state of dysphoria or reduced ability to experience reward (Watkins et al., 2000a; Vlachou et al., 2011). Hyperalgesia, a withdrawal symptom that may be considered partly somatic and partly affective, is also observed in rodents following spontaneous or mecamylamine-induced withdrawal from chronic non-contingent nicotine delivery (Schmidt et al., 2001; Damaj et al., 2003; Jackson et al., 2009, 2010). Hyperalgesia in such studies is operationally defined as increased sensitivity to nociceptive stimuli, usually in the form of tail-flick or hot-plate tests of latency to respond to noxious thermal stimuli.

Non-contingent exposure to nicotine is a simple and efficient way to induce nicotine dependence in animals and led to a great deal of findings regarding the possible neurobiological mechanisms of reward, dependence, and withdrawal (Malin, 2001; Malin and Goyarzu, 2009). However, the validity of this approach is limited when one wants to specifically investigate the neurobiological mechanisms that underlie the transition from occasional to compulsive use. Most importantly, contingent drug exposure (i.e., cigarette smoking and nicotine self-administration) and noncontingent exposure have very different psychological and physiological effects and recruit different brain systems (Dworkin et al., 1995; Markou et al., 1999). Nicotine absorption through subcutaneous or intraperitoneal administration is much slower than that achieved through inhalation, and the speed of administration has been shown to critically influence the reinforcing effects of drugs 
of abuse (Liu et al., 2005; Sorge and Clarke, 2009; but see Crombag et al., 2008). While minipumps deliver nicotine $24 \mathrm{~h}$ per day at a constant rate, humans smoke nicotine intermittently and not during sleep. Finally, the daily amount of nicotine typically delivered by minipumps $(3.16 \mathrm{mg} / \mathrm{kg})$ is similar to an average adult who smokes five packs of cigarettes, an amount consumed only by exceptionally heavy smokers (Armitage et al., 1975; Benowitz and Jacob, 1984). However, when differences between the metabolic rate of rats (nicotine half life $=45 \mathrm{~min}$; Adir et al., 1976; Plowchalk et al., 1992) and humans (half life $=2 \mathrm{~h}$ ) are taken into account, the actual disparity between the amounts absorbed is minimized (Malin, 2001), although comparisons remain difficult.

\section{NICOTINE SELF-ADMINISTRATION}

The self-administration method assesses an animal's propensity to self-administer a drug delivered (usually intravenously) contingently upon the emission of an operant response, usually a lever-press or nosepoke (Meisch and Lemaire, 1993). Since the early 1980s, an increasing number of laboratories have reported reliable rates of operant responding in nicotine self-administration studies with rodents (Corrigall and Coen, 1989; Donny et al., 1995; Watkins et al., 1999; Corrigall et al., 2000), but compared with other drugs of abuse, stable rates of nicotine self-administration remains difficult to establish and require careful control of a relatively high number of experimental parameters, such as the drug infusion duration, prior food training, restricted diets, and the need for cued infusions of nicotine (Henningfield and Goldberg, 1983; Collins et al., 1990; Stolerman and Jarvis, 1995; Le Foll and Goldberg, 2005; Chaudhri et al., 2006). At least some of the described difficulties obtaining nicotine self-administration may be related to the aversive properties of the drug (Benowitz, 1990). The difference between the rewarding and aversive doses of nicotine appears to be relatively small. Specifically, rats will intravenously self-administer nicotine at doses of $0.01-0.06 \mathrm{mg} / \mathrm{kg}$ (e.g., Corrigall and Coen, 1989; Donny et al., 1995; Shoaib et al., 1997), while an intravenous nicotine dose of $0.1 \mathrm{mg} / \mathrm{kg}$ has been reported to cause seizures (Hanson et al., 1979; Corrigall and Coen, 1989). Thus, when the behavioral criteria for demonstrating nicotine's reinforcing properties require that animals repeatedly self-administer the drug, the likelihood of an accumulating blood nicotine concentration that is no longer within the reinforcing dose range is greatly elevated (see Rose and Corrigall, 1997).

\section{ESCALATION OF NICOTINE SELF-ADMINISTRATION}

Rats allowed 1-3 h/day access to nicotine self-administration maintain stable and relatively low intake for weeks, exhibit very limited, if any, spontaneous withdrawal symptoms, and do not show increased motivation for nicotine after abstinence (Paterson and Markou, 2004; George et al., 2007; Cohen et al., 2012). The model of limited access to drug self-administration is highly relevant to the positive-reinforcement processes that account for the initiation and maintenance of occasional/recreational drug users but not for the transition to drug dependence, which is characterized in humans by escalated drug intake (Koob et al., 2004), robust somatic and affective withdrawal symptoms, and most importantly increased motivation for nicotine after protracted abstinence (Perkins et al., 2009). In contrast, rats exposed to extended (6-23 h) daily opiate, cocaine, or methamphetamine selfadministration sessions show escalation in drug intake (Ahmed and Koob, 1998, 1999; Ahmed et al., 2000; Ben-Shahar et al., 2004; Greenwell et al., 2009) that is characterized by an upward shift in the dose-effect function that could not be simply explained as the result of a change in the sensitivity to the drug (i.e., pharmacological tolerance or sensitization; Koob and Le Moal, 1997; Ahmed and Koob, 1998). It has been hypothesized that the escalation of drug intake reflects an allostatic increase in the hedonic set point as a result of downregulation of brain reward systems and recruitment of brain stress systems (Ahmed and Koob, 1998; Koob and Kreek, 2007). In line with this hypothesis, the escalation of opiate and cocaine intake is correlated with a progressive elevation in baseline reward thresholds (Ahmed et al., 2002; Kenny et al., 2006). Further supporting the validity of the escalation model for human addiction, the escalation of cocaine self-administration has also been shown to be accompanied by increased susceptibility to reinstatement (Mantsch et al., 2004; Wakabayashi et al., 2010) and increased stress reactivity (Aujla et al., 2008). However, the escalation of nicotine intake is not observed when rats are allowed daily extended access (6-24 h/day; 20-40 days) to nicotine (Cox et al., 1984; Valentine et al., 1997; DeNoble and Mele, 2006; Kenny and Markou, 2006; O’Dell et al., 2007), despite exhibiting levels of nicotine intake similar to human smokers (rats: $0.2-1.5 \mathrm{mg} / \mathrm{kg} /$ day; humans: $0.14-1.14 \mathrm{mg} / \mathrm{kg} / \mathrm{day}$; Benowitz and Jacob, 1984), and physical dependence as measured by spontaneous and mecamylamine-precipitated somatic signs (Paterson and Markou, 2004; O'Dell et al., 2007). Moreover, in contrast to the increased reward thresholds observed after extended access to cocaine, heroin, and methamphetamine, repeated exposure to nicotine self-administration (1-12 h/day for 20 days) has been shown to induce a long-lasting decrease in reward thresholds (Kenny and Markou, 2006), a result opposite to that observed after chronic exposure to osmotic minipumps (Epping-Jordan et al., 1998; Watkins et al., 2000a; see Figure 1). These results suggest either that nicotine dependence differs from dependence on the other drugs of abuse or that modeling the transition to escalation of compulsive nicotine intake requires revision of the existing model.

As discussed above, nicotine dependence commonly develops as adolescents and young adults who smoke intermittently escalate their drug intake. It has been repeatedly shown that intermittent access to alcohol leads to higher levels of alcohol intake than continuous access, suggesting that neurobiological changes that underlie dependence may be more readily triggered by repeated cycles of withdrawal followed by increased intake (Sinclair and Senter, 1967; O’Dell et al., 2004; Lopez and Becker, 2005; Becker and Baros, 2006). Thus, a model of dependence-induced excessive nicotine intake was developed in our laboratory, in which rats are allowed to self-administer nicotine 4 days per week for either $23 \mathrm{~h} /$ day (extended access) or $1 \mathrm{~h} /$ day (limited access), followed by 2-3 days of abstinence. Rats with extended access exhibit a pronounced increase in nicotine intake in the first post-abstinence session, with a gradual return to baseline intake levels within the remaining three daily sessions (George et al., 2007; O'Dell and Koob, 2007). This nicotine deprivation effect does not occur in rats with limited access to nicotine, suggesting that the extended-access 
model has better validity for studying the increased motivation for nicotine during abstinence. Moreover, 1-12 h/day of access to nicotine self-administration results in either decrease or no change in brain reward threshold during abstinence (Kenny and Markou, 2006; Patterson et al., 2008), while extending the access to $22 \mathrm{~h} /$ day produces an increase in brain reward threshold during the first 3 days of abstinence (measured during extinction of nicotine selfadministration, Harris et al., 2011). This result is in accordance with the increase in brain reward threshold observed during withdrawal (Epping-Jordan et al., 1998) and conditioned withdrawal (Kenny and Markou, 2005) after chronic exposure to nicotine minipump, and with the increase dysphoria, depressed mood, anxiety, and frustration reported in humans during abstinence (Hughes et al., 1991).

Based on these results, we developed a novel animal model of the escalation of nicotine intake, in which rats have extended $(21 \mathrm{~h} /$ day) but intermittent (every $24-48 \mathrm{~h}$ ) access to nicotine self-administration $(0.03 \mathrm{mg} / \mathrm{kg})$. Escalation occur only when the rats are allowed extended but not limited access (Cohen et al., 2012), and is associated with increased motivation to take nicotine on a progressive-ratio schedule of reinforcement and with a more intense somatic signs following precipitated withdrawal. In line with the hypothesis that tobacco smoking is more reinforcing/addictive than pure nicotine because of non-nicotine compounds, such as monoamine oxidase inhibitors (MAOIs; Berlin and Anthenelli, 2001; Fowler et al., 2003; Guillem et al., 2005, 2006), the escalation is dramatically increased when rats are pretreated with the MAOI phenelzine ( $2 \mathrm{mg} / \mathrm{kg}$, i.p.) $)$ prior to each extended-access self-administration session.

As stated above, limited access (1-12 h/day) to nicotine selfadministration does not produce escalation of nicotine intake, however, a recent report showed that rats with limited access to nicotine self-administration ( $2 \mathrm{~h} /$ day) escalate their nicotine intake if they are given access to nicotine 8-12 h into withdrawal from exposure to nicotine vapor (Gilpin et al., 2013). Considering that this exposure to nicotine vapor was sufficient to produce robust withdrawal symptoms (Gilpin et al., 2013), it suggests that emergence of a negative withdrawal syndrome is required for the development of escalation of nicotine intake (George et al., 2007; Gilpin et al., 2013), and suggest that exposure to nicotine vapor either passively (second-hand smoking) or actively (electronic cigarette) may have profound consequences on the acquisition and relapse of smoking behavior.

\section{EFFECTS OF NICOTINE EXPOSURE AND WITHDRAWAL IN ADOLESCENCE}

Converging lines of evidence suggest that adolescence is a vulnerable period in the development of tobacco addiction (O'Dell, 2009). Specifically, compared to adult, adolescent rats show increased sensitivity to the rewarding effects of nicotine as measured with both self-administration (Levin et al., 2003; Chen et al., 2007) and the CPP procedures (Belluzzi et al., 2004; Shram et al., 2006; Torres et al., 2008). On the other hand, adolescent rats demonstrate lower aversive responses to high nicotine doses measured with CPA and conditioned taste aversion (Shram et al., 2006; Torres et al., 2008). Interestingly, adolescent rats may be more sensitive also to the contribution of non-nicotinic tobacco smoke ingredients of tobacco as acetaldehyde, a major component of tobacco smoke, appears to more readily enhance nicotine self-administration in adolescent but not adult rats (Belluzzi et al., 2005).

In addition to the increased rewarding effects and reduced aversive effect of nicotine in adolescents, studies using models of withdrawal from chronic passive nicotine delivery suggest that adolescent rats have a more benign nicotine withdrawal syndrome, as reflected by lower levels of somatic signs (O'Dell et al., 2004; Shram et al., 2008), withdrawal thresholds (O'Dell et al., 2006), CPA (O'Dell et al., 2007), and anxiety-like behavior in the elevated plus maze (Wilmouth and Spear, 2006).

Importantly, the human data on adolescence as a critical period in the establishment of smoking behavior in adulthood is supported by the finding that exposure to nicotine during adolescence is associated with enhanced rewarding effects of nicotine. For example, adult rats that initiated nicotine self-administration during adolescence, show higher levels of nicotine intake than rats that initiated nicotine self-administration during adulthood (Adriani et al., 2003) and rats that received nicotine during adolescence show in adulthood greater nicotine-induced place preference (Adriani et al., 2006) and increased anxiety induced withdrawal (Slawecki et al., 2003). However, the transition from nicotine use to nicotine addiction (i.e., escalation) has not yet been examined in adolescent rats.

\section{EXPOSURE TO CIGARETTE SMOKE AND NICOTINE VAPOR}

Animal models that utilize inhalation as the route of administering cigarette smoke or nicotine have exceptional face validity because they best simulate the unique pharmacokinetic characteristics (i.e., rate of absorption and brain delivery) that are associated with smoking, which may have implications for its addictive properties (Benowitz, 1990). Moreover, the stimulation of the respiratory tract by tobacco smoke (e.g., by local nicotinic receptors; Ginzel and Eldred, 1977) may play a role in nicotine dependence (Rose and Corrigall, 1997). Another advantage of inhalation-based models is that they are non-invasive and much less labor-intensive than those that involve osmotic minipumps. Although current inhalation technology allows only for non-contingent passive exposure and not for self-administration, it is particularly suitable for the study of the detrimental effects of second hand smoke and their contribution to addiction in particular.

Automated smoke machines that deliver cigarette smoke to animals in exposure chambers have been used extensively to study the toxic effects of mainstream and sidestream ("second hand") tobacco smoke (Hecht, 2005; Farkas et al., 2006; Coggins, 2007). Particularly, chronic exposure to sidestream smoke simulating environmental tobacco smoke has been recently shown to induce behavioral and neurobiological changes in laboratory animals. In primates, prenatal and postnatal environmental smoke exposure induces neuronal damage to the cortex and midbrain (Slotkin et al., 2006) and impaired memory (Golub et al., 2007). In rats, chronic exposure during postnatal days 8-23 leads to perturbed mitochondrial processes in the cerebellum that is associated with a heightened locomotor response in a novel environment (Fuller et al., 2012). Similar chronic exposure during adulthood results in biochemical changes in several brain regions (hippocampus, cerebellum, frontal cortex) indicative of enhanced inflammatory 
processes and cell death (Fuller et al., 2010) as well as in learning and memory impairments (Jaques et al., 2012).

Repeated exposure to mainstream cigarette smoke (modeling exposure of active smokers) induces effects similar to those of nicotine injections, including $\mathrm{nAChR}$-dependent analgesia in rats, with the development of tolerance following repeated exposures (Anderson et al., 2004; Simons et al., 2005), sensitization to the effects of nicotine on locomotion (Suemaru et al., 1992; Bruijnzeel et al., 2009), and dependence as indicated by mecamylamineprecipitated somatic withdrawal signs and elevated reward thresholds (Small et al., 2010; Yamada et al., 2010). Small et al. (2010) reports that despite induction of a dependent state, nicotine selfadministration is decreased $24 \mathrm{~h}$ after the termination of 28 consecutive tobacco smoke exposure sessions ( $4 \mathrm{~h} /$ day) and returns to control levels 5 days later. However, these results need to be interpreted with caution because the levels of nicotine and carbon monoxide to which the rats were exposed were very high in most of these studies. For example, average plasma nicotine levels in dependent smokers are 10-50 ng/ml (Russell et al., 1980; Benowitz and Jacob, 1984; Henningfield and Keenan, 1993), and average blood carboxyhemoglobin (COHgb) saturation, resulting from carbon monoxide exposure, is $4-10 \%$ (Benowitz et al., 1982; Turner et al., 1986; Law et al., 1997). Plasma nicotine concentrations in the cigarette smoke exposure studies described above ranged from 38.5 (Bruijnzeel et al., 2009) to $95.4-188 \mathrm{ng} / \mathrm{ml}$ (Anderson et al., 2004; Small et al., 2010; Yamada et al., 2010). Although COHgb levels were not reported, carbon monoxide levels in the chambers [150-402 parts per million (PPM)] were $40-400 \%$ higher than the level needed to induce COHgb saturation of $10.5 \%$ (Harris et al., 2010). These are especially high compared with the values in non-smokers exposed to secondhand smoke $(5.9 \mathrm{ng} / \mathrm{ml}$ of serum nicotine; Pacifici et al., 1995) and carbon monoxide levels of 5-20 PPM (Office of Technology Assessment, 1986), leading to COHgb levels of $4.43 \%$ (Yee et al., 2010). In addition to nicotine, tobacco smoke contains at least 4,000 additional substances, many of which are toxic or psychoactive, further complicating data interpretation. For example, rats exposed to high levels of carbon monoxide and other toxins may develop adverse effects that will hinder their motivation to take nicotine. Alternatively, some components of tobacco smoke may negate certain effects of nicotine. This could explain the finding that although daily nicotine $(0.125 \mathrm{mg} / \mathrm{kg}$, s.c. $)$ reverses the elevated reward thresholds induced by withdrawal from chronic nicotine, cigarette smoke exposure that induces the same serum nicotine levels $(25-55 \mathrm{ng} / \mathrm{ml})$ did not (Harris et al., 2010). Thus, although cigarette smoke exposure uniquely allows the determination of the net effect of tobacco smoke, isolating the specific effects of different components of tobacco smoke is difficult.

The recently developed model of nicotine vapor (George et al., 2010; Gilpin et al., 2013) addresses this shortcoming. The vaporization of nicotine is achieved without the use of heat by constantly bubbling nicotine with air and allowing for the reliable induction of air-nicotine concentrations that induce blood nicotine levels comparable to those of different tobacco exposure levels (heavy smokers, moderate smokers, and second-hand smoking). Intermittent exposure to nicotine vapor $\left(0.2 \mathrm{mg} / \mathrm{m}^{3}\right.$ for $8 \mathrm{~h} /$ day for 7 days) produces a concentration of nicotine in the blood of $22 \mathrm{ng} / \mathrm{m}$, which is in the range of moderate smokers, and induces significant somatic withdrawal signs precipitated by mecamylamine (George et al., 2010). The concentration of nicotine in vapor chamber air can be adjusted to produce blood nicotine levels that are relevant to heavy, regular, or second-hand smoking and e-cigarette use. Moreover, as stated above, rats exposed to nicotine vapor $\left(7.5 \mathrm{mg} / \mathrm{m}^{3}\right.$ over a $12-\mathrm{h}$ period $)$ to the point of dependence produce an escalation of nicotine self-administration relative to both their own baseline (200\% increase) and non-dependent controls.

Thus, models based on the inhalation of tobacco smoke or pure nicotine have the potential to reliably detect the biological mechanisms that are unique to the consumption of tobacco via smoking and determine the possible contribution of constituents in second-hand smoke, particularly nicotine, in the transition to nicotine dependence, reflected by the escalation of nicotine intake. Future studies will need to address this issue using relatively low levels of nicotine/smoke exposure and examine the effects of exposure to a combination of nicotine and certain other selected constituents of tobacco smoke (e.g., acetaldehyde and harman) on different aspects of tobacco dependence. Finally, nicotine vapor is the only model available to date that can be used to investigate the neurobiological effects of nicotine delivery by e-cigarettes on the vulnerability to develop nicotine dependence and relapse.

\section{NEUROBIOLOGICAL MECHANISIMS OF NICOTINE ADDICTION}

The different animal models of nicotine abuse and dependence have been widely used to unveil the neurobiological mechanisms that mediate the acute and chronic effects of nicotine. Models of the acute reinforcing effects of nicotine were established more than two decades ago, and the biological processes involved are well-characterized. In contrast, the neurobiological mechanisms that mediate the increased motivation for nicotine associated with drug dependence are poorly known.

\section{ACUTE EFFECTS OF NICOTINE Nicotine acetylcholine receptors}

Nicotine acetylcholine receptors are distributed throughout the central nervous system (Paterson and Nordberg, 2000), and their activation increases the release of various neurotransmitters (Wilkie et al., 1993; McGehee et al., 1995; Clarke and Reuben, 1996; Pontieri et al., 1996; Yang et al., 1996). The acute reinforcing and rewarding effects of nicotine are mediated by the activation of nAChRs, which are composed of five subunits that can either be homomeric or heteromeric (Millar and Gotti, 2009). Twelve different neuronal nAChR subunits $(\alpha 2-\alpha 10$ and $\beta 2-\beta 4)$ have been identified (Dani and Bertrand, 2007). Inactivation of $\alpha 7-, \alpha 4-$, $\alpha 6-$, and $\beta 2$-containing $\mathrm{nAChRs}$ by pharmacological or genetic manipulations decrease nicotine self-administration in rodents (Picciotto et al., 1988; Dwoskin et al., 1999; Markou and Paterson, 2001). These subunits likely mediate the acute reinforcing effects of nicotine. In contrast, $\alpha 5$ knockout mice show increased nicotine self-administration at a high unit dose, suggesting the involvement of this subunit in mediating the aversive effects of high nicotine doses (Fowler et al., 2011). 


\section{Mesocorticolimbic system: dopamine}

The acute reinforcing effects of nicotine and other drugs of abuse are in part mediated by activation of the mesocorticolimbic dopamine system (Koob and Le Moal, 2008). The mesocorticolimbic dopamine system includes dopaminergic neurons that originate in the ventral tegmental area (VTA) and project to the nucleus accumbens (NAc), hippocampus, amygdala, and prefrontal cortex (PFC). Indeed, nicotine exposure increases dopamine release in mesolimbic terminal fields (Di Chiara, 2000). Rats will selfadminister nicotine directly into the VTA (Ikemoto et al., 2006), and intra-VTA infusion of a nicotine antagonist decreases nicotine self-administration (Corrigall et al., 1994). In addition, disruption of dopamine transmission either systemically or in the VTA attenuates nicotine self-administration (Corrigall and Coen, 1991) and prevents the reduction of brain reward thresholds induced by nicotine (Huston-Lyons et al., 1993). In the place preference procedure, dopamine antagonists block nicotine-induced CPP (Acquas et al., 1989), but in a study by Laviolette and van der Kooy (2003), nicotine infusion into the VTA dose-dependently induced CPA at low dose and CPP at high doses, and systemic infusion of a dopamine antagonist potentiated the rewarding effects of mid-range nicotine doses and switched the motivational effects of a low concentration from aversive to rewarding. These results appear to be contradictory to those obtained with the self-administration model (Ikemoto et al., 2006) and may suggest different roles for dopamine in mediating specific functions of reward and reinforcement that may be dose-dependent.

\section{Glutamate, GABA, and acetylcholine}

Nicotine increases dopamine neurotransmission in the mesocorticolimbic system by activating nAChRs, particularly $\alpha 4 \beta 2$, on dopaminergic neurons in the VTA (Nisell et al., 1994; Mansvelder and McGehee, 2003) and nAChRs, particularly $\alpha 7$-containing glutamatergic neurons that originate in the VTA, NAc, amygdala, hippocampus, and PFC (Fu et al., 2000; Mansvelder and McGehee, 2003) and project to dopaminergic neurons in the VTA (Grillner and Svensson, 2000). Consequently, antagonists of various glutamate receptors, including NMDA, AMPA, and mGluR5, decrease nicotine self-administration, whether delivered systemically or into the VTA (Kenny et al., 2003, 2009; Patterson et al., 2003; Liechti and Markou, 2008), and NMDA and AMPA receptor antagonists block nicotine-induced dopamine release in the NAc (Kosowski et al., 2004). Moreover, lesions of glutamatergic inputs from the pedunculopontine tegmental nucleus (PPT) to VTA inhibit nicotine self-administration and CPP (Lança et al., 2000; Laviolette et al., 2002; Picciotto and Corrigall, 2002). The PPT also contains cholinergic neurons that are activated by nicotine and project to dopaminergic neurons in the VTA. Indeed, delivery of an antagonist of non- $\alpha 7 \mathrm{nAChR}$ to the PPT or lesions of cholinergic neurons in the PPT reduced nicotine self-administration (Lança et al., 2000; Corrigall et al., 2001, 2002; Alderson et al., 2006). Finally, intra-VTA GABAergic neurons are activated by nicotine and inhibit dopamine neurons. However $\mathrm{nAChR}$ on GABAergic neurons desensitize faster than nAChRs on dopamine neurons, leading to a facilitation of dopamine neuron firing (Laviolette and van der Kooy, 2004). Accordingly, enhanced activation of $\mathrm{GABA}_{\mathrm{B}}$ receptors inhibits nicotine self-administration and CPP in rats (Patterson et al., 2004, 2008; Le Foll et al., 2008).

\section{Endogenous opioids}

The endogenous opioid system may also play an important role in the rewarding and reinforcing effects of nicotine (for review, see Berrendero et al., 2010). Briefly, endogenous opioid systems include three main receptors, $\mu$ (MOR), $\delta$ (DOR), and $\kappa$ (KOR; Kieffer and Evans, 2009). Of the opioid peptides in the brain, $\beta$-endorphin binds with a higher affinity to MORs than DORs or KORs, and it is a main endogenous ligand for MORs. Dynorphins are the main endogenous ligands for KORs (Roth-Deri et al., 2008). Nicotine enhances the release of endogenous opioid peptides and modifies the expression of their receptors. For example, acute nicotine induces increases in met-enkephalin, dynorphin, and prodynorphin mRNA in the striatum of mice after acute nicotine injection (Dhatt et al., 1995; Isola et al., 2009). Nicotineinduced dopamine increase in the NAc can be blocked by the administration of MOR antagonists or KOR agonists (Maisonneuve and Glick, 1999). However, although systemic inhibition of $\beta$-endorphin-MORs by pharmacological or genetic manipulations generally reduces the rewarding effects of nicotine in animal models (Berrendero et al., 2002; Göktalay et al., 2006; Trigo et al., 2009), the blockade of opioid receptors in the VTA and NAc does not interfere with nicotine self-administration in rats (Corrigall and Coen, 1991; Corrigall et al., 2000). Interestingly, prodynorphin knockout mice show enhanced acquisition of nicotine self-administration (Galeote et al., 2009), suggesting that the prodynorphin-KOR system may mediate the aversive effects of nicotine, particularly at high doses, as was demonstrated with other drugs of abuse (Mendizábal et al., 2006; Shippenberg et al., 2007).

\section{Serotonergic system}

Serotonin [5-hydroxytryptamine (5-HT)] neurons in the median and dorsal raphe nuclei provide the majority of 5-HT innervation to the forebrain and are associated with appetitive behavior and affect regulation (Steinbusch, 1984). Their involvement in nicotine reinforcement is suggested by nicotine-induced increases in dorsal raphe neuron firing and 5-HT release (Ribeiro et al., 1993; Li et al., 1998; Mihailescu et al., 1998, 2002; Martinez-Gonzalez et al., 2002). Agonists of 5- $\mathrm{HT}_{2 \mathrm{C}}$ receptors reduce nicotine selfadministration (Grottick et al., 2001) but not nicotine-induced CPP (Hayes et al., 2009).

\section{Endocannabinoids}

Endocannabinoid systems may also be involved in the rewarding and reinforcing effects of nicotine. $\mathrm{CB}_{1}$ receptor antagonists decrease nicotine self-administration and CPP in rodents (Cohen et al., 2002; Le Foll and Goldberg, 2004; Merritt et al., 2008) and the nicotine-induced enhancement of dopamine levels in the NAc (Cohen et al., 2002).

\section{CHRONIC NICOTINE AND WITHDRAWAL}

The pathological motivational state that characterizes dependence on nicotine involves the appearance of negative affective states when nicotine exposure is discontinued (i.e., nicotine withdrawal). 
These may involve disruptions of the same neurobiological mechanisms that are involved in the positive reinforcing effects of the drug (i.e., within-system neuroadaptations) and recruitment of stress systems (e.g., between-system neuroadaptations). This negative affective state may represent a negative reinforcer that will enhance the incentive value of nicotine, leading to increased nicotine intake in an attempt to alleviate the negative emotional state (Solomon and Corbit, 1973; Koob and Le Moal, 2001, 2008; Koob, 2008, 2010).

Spontaneous or precipitated withdrawal from chronic nicotine produces anxiety-like behavior, CPA, and elevations of brain reward thresholds (Balerio et al., 2004; Jackson et al., 2008; Johnson et al., 2008). These affective and reward deficits likely involve downregulation of dopaminergic neurotransmission in the mesocorticolimbic system. Withdrawal from chronic nicotine results in decreased tonic firing of dopamine neurons in the VTA (Grieder et al., 2012) and decreases dopamine levels in the NAc (Fung et al., 1996; Hildebrand et al., 1998). Chronic exposure to nicotine produces a desensitization of nAChRs (Dani and Heinemann, 1996; Fenster et al., 1999; Picciotto et al., 2008) and an upregulation of nAChRs (Marks et al., 1983, 1992; Changeux et al., 1984; Dani and Heinemann, 1996; Koob and Le Moal, 2005). However, differences exist between nAChRs. For example, brain nicotine concentrations in an average smoker reach levels sufficient to desensitize $\alpha 4 \beta 2 \mathrm{nAChRs}$ without affecting $\alpha 7 \mathrm{nAChRs}$, which requires much higher concentrations (Wooltorton et al., 2003). Glutamate release is regulated by $\alpha 7 \mathrm{nAChRs}$ located presynaptically (Marchi et al., 2002). Thus, during nicotine exposure, desensitization of $\alpha 4 \beta 2$ nAChRs on GABAergic neurons will suppress GABA release and inhibit dopamine neurons in the VTA, whereas $\alpha 7 \mathrm{nAChRs}$ on glutamatergic afferents will remain active and increase glutamate release on dopamine neurons in this region, facilitating dopamine secretion in the NAc (Dani, 2001; Wooltorton et al., 2003). However, nicotine withdrawal produces an opposite effect, with decreases in VTA glutamate levels and increases in VTA GABA levels (Natividad et al., 2012). Consequently, antagonism of presynaptic mGluR2/3 antagonists, known to negatively modulate glutamate release (Schoepp et al., 2003), attenuates reward deficits associated with nicotine withdrawal in rodents and alleviates the depressive-like symptoms related to nicotine abstinence in humans (Kenny et al., 2003; Liechti and Markou, 2008). Inhibition of glutamate transmission by the delivery of mGluR5 antagonists in rats and knocking out mGluR5 in mice further elevates reward thresholds during nicotine withdrawal (Harrison et al., 2002; Liechti and Markou, 2007; Stoker et al., 2012).

Endogenous opioids may play an important role in the development of nicotine dependence, reflected by the resemblance between the somatic signs induced by the cessation of nicotine exposure and those of opiate withdrawal (Malin et al., 1993; Watkins et al., 2000a) and the ability of the opioid receptor naloxone to induce somatic signs of withdrawal in heavy smokers (Sutherland et al., 1995; Krishnan-Sarin et al., 1999). Naloxone administration in rodents chronically treated with nicotine induces somatic signs of withdrawal (Malin et al., 1993; Balerio et al., 2004; Biala et al., 2005), CPA, and elevations in reward thresholds (Watkins et al., 2000a,b). MOR (Berrendero et al., 2002) and proenkephalin (Berrendero et al., 2005) knockout mice chronically exposed to nicotine show reduced somatic signs of withdrawal. Interestingly, knockout of the prodynorphin gene does not impact the somatic signs of nicotine withdrawal (Galeote et al., 2009). Moreover, nicotine withdrawal is associated with increased prodynorphin expression in the NAc (Isola et al., 2008). Thus, it can be hypothesized that during chronic nicotine exposure, there is a release of opioid peptides, which leads to downregulation of MORs and upregulation of prodynorphin-KOR systems. These opposing effects may combine to participate in the mediation of the somatic and affective aspects of nicotine withdrawal.

There is also evidence that 5 -HT neurotransmission is involved in the mediation of nicotine dependence. Chronic nicotine treatment decreases the concentration of 5-HT in the hippocampus and increases the number of hippocampal 5- $\mathrm{HT}_{1 \mathrm{~A}}$ receptors (Benwell and Balfour, 1979). This receptor upregulation may reflect reduced levels of 5-HT input from the median raphe nucleus, which is the main source of brain 5-HT and projects to various brain areas, including the hippocampus and amygdala (Benwell et al., 1990). During nicotine abstinence, decreased 5-HT, combined with upregulated $5 \mathrm{HT}_{1}$ receptors, may contribute to symptoms of depression and anxiety that are associated with 5-HT deficits (Coppen, 1967; Young et al., 1985; Markou et al., 1998) and nicotine withdrawal (Hughes et al., 1991). Indeed, antagonism of 5-HT receptors attenuates withdrawal-induced CPA in animals (Suzuki et al., 1997) and anxiety in withdrawn human smokers (West et al., 1991; Hilleman et al., 1992, 1994). Interestingly, a recent study suggests that acute nicotine activates 5 -HT neurons in the dorsal raphe that are regionally distinct from those involved in nicotine withdrawal (Sperling and Commons, 2011).

\section{STRESS IN NICOTINE DEPENDENCE}

Convergent lines of evidence (Koob and Le Moal, 2001, 2005) suggest that stress [e.g., corticotropin-releasing factor (CRF) and orexin] and anti-stress [e.g., neuropeptide Y (NPY)] systems are involved in the emotional and motivational aspects of drug dependence (see Bruijnzeel, 2012, for an extensive review) and are largely localized to the extended amygdala, a forebrain macrostructure composed of the bed nucleus of he stria terminalis (BNST), central nucleus of the amygdala (CeA), and NAc shell (Heimer and Alheid, 1991; Smith and Aston-Jones, 2008).

\section{Corticotropin-releasing factor}

Nicotine self-administration increases the release of adrenocorticotropic hormone (ACTH) and cortisol/corticosterone (CORT; Donny et al., 2000; Chen et al., 2008). Evidence suggests that while CORT facilitates the reinforcing effects of drugs in nondependent subjects, high circulating levels of CORT, as a result of repeated drug use, can feed back to shut off the hypothalamicpituitary adrenal (HPA) axis and sensitize extrahypothalamic CRF systems, contributing to escalated and compulsive drug intake (Vendruscolo et al., 2012). CRF is a neuropeptide that has three paralogs - Ucn 1,2, and 3 - and is involved in regulating the neuroendocrine autonomic and behavioral responses to stress (Vale et al., 1981, 1983; Dunn and Berridge, 1990; Koob, 1999). Two G-protein-coupled CRF receptors have been identified: $\mathrm{CRF}_{1}$ and $\mathrm{CRF}_{2}$. Notably, although CRF and Ucn 1 have high selectively for the $\mathrm{CRF}_{1}$ receptor, $U \mathrm{cn} 2$ and $U \mathrm{cn} 3$ have high selectivity for 
the $\mathrm{CRF}_{2}$ receptor (Bale and Vale, 2004). While activation of the $\mathrm{CRF}_{1}$ receptor leads to increases in anxiety-like behavior, activation of the $\mathrm{CRF}_{2}$ receptor generally triggers a compensatory anti-stress response. For example, selective $\mathrm{CRF}_{1}$ antagonists have been shown to reduce anxiety-like behavior in animals (Griebel et al., 1998; Deak et al., 1999; Zorrilla et al., 2002), whereas the $\mathrm{CRF}_{2}$ receptor agonist $\mathrm{Ucn} 3$ decreases behavioral stress responses (Valdez et al., 2002, 2003). Various findings suggest that recruitment of $C R F-C_{1} F_{1}$ systems, particularly in regions of the extended amygdala, may be involved in producing the negative emotional states during withdrawal or protracted abstinence from chronic nicotine. First, precipitated nicotine withdrawal increases Fos expression (i.e., neuronal activation) in the CeA. Second, CRF levels in the basal forebrain (Matta et al., 2007) and CeA (George et al., 2007) are elevated during nicotine withdrawal. Third, the elevation of reward thresholds induced by nicotine withdrawal is attenuated by intracerebroventricular or intra-CeA infusion of the $\mathrm{CRF}_{1}$ antagonist $\mathrm{D}-\mathrm{Phe} \mathrm{CRF}_{12-41}$ and non-specific CRF antagonist $\alpha$-helical $\mathrm{CRF}_{9-41}$ (Bruijnzeel et al., 2009; Marcinkiewcz et al., 2009; Bruijnzeel, 2012) but not a $\mathrm{CRF}_{2}$ antagonist (Bruijnzeel et al., 2009). Infusion of D-Phe $\mathrm{CRF}_{12-41}$ into the NAc shell, another region of the extended amygdala, also blocks the withdrawalinduced elevation in reward thresholds (Marcinkiewcz et al., 2009). Fourth, a CRF 1 antagonist (MPZP) administered systemically attenuates the abstinence-induced increases in nicotine intake and nicotine withdrawal-induced anxiety-like behavior (George et al., 2007). Finally, $\mathrm{CRF}_{1}$ antagonists administered systemically attenuate the escalated intake of heroin and cocaine in rats with extended access to the drug (Specio et al., 2008; Greenwell et al., 2009).

\section{Neuropeptide $\boldsymbol{Y}$}

Neuropeptide Y is a 36-amino-acid polypeptide with powerful anxiolytic-like properties in various animal models of anxiety and stress (Heilig and Murison, 1987; Broqua et al., 1995; Sajdyk et al., 1999; Tovote et al., 2004). The involvement of NPY in addiction was mainly studied with regard to alcohol dependence, with alcohol-preferring rats having lower basal levels of NPY in the CeA that correlate with greater levels of anxiety-like behavior compared with alcohol non-preferring rats (Suzuki et al., 2004; Pandey et al., 2005). Moreover, viral vector-induced overexpression of NPY in the CeA decreases alcohol intake in alcohol-dependent rats (Thorsell et al., 2007). These results suggest that downregulation of the NPY system in the CeA may mediate the transition from non-dependent to dependent alcohol intake. The role of NPY in nicotine dependence has been less studied. Rylkova et al. (2008) report that NPY prevents the somatic signs of withdrawal but not elevation in brain reward thresholds that result from precipitated nicotine withdrawal in rats. Yet, abstinence from nicotine induced anxiety-like behavior that was associated with a decreased ratio of NPY to CRF in the amygdala, suggesting an allostatic change in both stress and anti-stress neuropeptide systems (Slawecki et al., 2005; Aydin et al., 2011).

\section{Norepinephrine}

Several lines of evidence suggest that norepinephrine (NE) signaling from the nucleus tractus solitarius (NTS) to extended amygdala mediates the aversive effects of opiate and cocaine withdrawal (e.g., anxiety-like behavior; Smith and Aston-Jones, 2008). Moreover, morphine withdrawal enhances subsequent morphine-induced CPP, which is reduced by delivery of the $\alpha_{2}$-adrenoceptor agonist clonidine (Nader and van der Kooy, 1996). The role of NE in nicotine dependence has been less explored, but clonidine appears to decrease anxiety and irritation associated with smoking cessation and promote abstinence (Prochazka et al., 1992; Gourlay et al., 2004). The few animal studies conducted have yielded conflicting results. Deficits in brain reward function during nicotine withdrawal were attenuated by antagonism of $\alpha_{1}$-adrenoceptors (Bruijnzeel et al., 2010) and antagonism of $\alpha_{2}$-adrenoceptors in another study (Semenova and Markou, 2010). This is puzzling given the positive effect of clonidine, a $\alpha_{2}$ agonist, in human abstinent smokers. More studies are needed to clarify the role of NE in nicotine dependence.

\section{Orexin/hypocretin}

Orexin A (hypocretin-1) and orexin B (hypocretin-2) are neuropeptides that have two known receptors, Hcrt-r1 and Hcrt-r2, and regulate several processes, including arousal (Sutcliffe and de Lecea, 2002; Taheri et al., 2002) and stress responses (Baldo et al., 2003; Winsky-Sommerer et al., 2004). Orexin/hypocretin neurons are especially abundant in the lateral hypothalamus and project to various brain regions, including the extended amygdala (Peyron et al., 1998; Baldo et al., 2003). Interestingly, intracerebroventricular infusion of orexin A induces Fos activation in approximately half of the CRF-containing neurons in the CeA (Sakamoto et al., 2004). Orexin neurons also receive inputs from the amygdala (Sakurai et al., 2005), and a possible positive feedback circuit between hypothalamic orexin neurons and amygdala CRF neurons has been suggested (Corrigall, 2009). Indeed, dependent smokers during early withdrawal show a significant negative correlation between hypocretin plasma concentration and nicotine craving (von der Goltz et al., 2010). A recent study reports that nicotine withdrawal increases hypocretin cell activity in the hypothalamus and that the hypocretin-1 receptor antagonist SB334867 as well as preprohypocretin knockout attenuate somatic nicotine withdrawal signs in mice (Plaza-Zabala et al., 2012). This study also revealed that the hypothalamic paraventricular nucleus (PVN) is strongly involved in this effect. Infusion of SB334867 into this region attenuates the somatic signs of withdrawal.

\section{Nociceptin/orphanin FQ}

Nociceptin/orphanin FQ is a 17 -amino-acid peptide that shows structural homology with the dynorphin A peptide (Reinscheid et al., 1995) and binds to the nociceptin/orphanin peptide (NOP) receptor. Nociceptin/orphanin FQ and NOP receptors are distributed throughout the central nervous system, with relatively high densities in the extended amygdala, PFC, and VTA (Neal et al., 1999). Nociceptin/orphanin FQ generally inhibits stress responses by functionally antagonizing CRF activity (Ciccocioppo et al., 2003). Chronic exposure to alcohol decreases the levels of brain nociceptin/orphanin FQ (Lindholm et al., 2002), and activation of the nociceptin/orphanin FQ system attenuates alcohol withdrawal symptoms and reverses increased anxiety-like behavior associated with ethanol dependence (Economidou et al., 
2011; Aujla et al., 2013). Nociceptin/orphanin FQ might be similarly involved in nicotine dependence. NOP receptor knockout mice, unlike wildtype mice, show a significant mecamylamineinduced CPA to nicotine withdrawal (Sakoori and Murphy, 2009).

\section{ESCALATION OF NICOTINE INTAKE}

Unlike cocaine and opiates, daily extended self-administration sessions do not induce escalation of nicotine intake but rather a reduction in intake following the first daily session and stable intake afterward (Valentine et al., 1997; Kenny and Markou, 2006; O'Dell et al., 2007; Cohen et al., 2012). However, humans typically do not have continuous access to smoking but instead alternate between periods of access (daytime) and no access (nighttime). The escalation of nicotine intake only occurs when 24-48 $\mathrm{h}$ of abstinence are given between extended-access $(21 \mathrm{~h})$ sessions (Cohen et al., 2012). It is possible that escalation does not take place when given continuous access because of nAChR desensitization (see above), which requires a period ranging from a few hours to a few days to recover (Collins et al., 1990, 1994; Girod and Role, 2001). Additionally, the escalated intake of nicotine could reflect the increased incentive value of nicotine that results from experiencing a negative affective state because of recruitment of stress systems and downregulation of anti-stress systems (Koob and Le Moal, 2001; Koob, 2010). Supporting such a hypothesis, CRF levels in the CeA are increased during precipitated withdrawal. Moreover, blocking $\mathrm{CRF}_{1}$ receptors systemically with MPZP attenuates both the increase in anxiety-like behavior during precipitated withdrawal and increase in nicotine intake following $72 \mathrm{~h}$ of abstinence (George et al., 2007). In accordance with the hypothesis that emergence of a negative emotional state is required in order to observe escalation of nicotine intake is the fact that rats with limited access to nicotine self-administration $(2 \mathrm{~h} /$ day) escalate their nicotine intake only if they are tested under withdrawal from daily exposure to nicotine vapor that is sufficient to produce a robust withdrawal syndrome (Gilpin et al., 2013).

To further support the hypothesis that negative affective symptoms drive the escalation of nicotine self-administration, possible associations between anxiety-like behavior (among other

\section{REFERENCES}

Acquas, E., Carboni, E., Leone, P., and Di Chiara, G. (1989). SCH 23390 blocks drug-conditioned placepreference and place-aversion: anhedonia (lack of reward) or apathy (lack of motivation) after dopamine-receptor blockade? Psychopharmacology (Berl.) 99, 151-155. doi:10.1007/BF00442800

Adir, J., Miller, R. P., and Rotenberg, K. S. (1976). Disposition of nicotine in the rat after intravenous administration. Res. Commun. Chem. Pathol. Pharmacol. 13, 173-183.

Adriani, W., Deroche-Gamonet, V., Le Moal, M., Laviola, G., and Piazza, P. V. (2006). Preexposure during or following adolescence differently affects nicotine-rewarding properties in adult rats. Psychopharmacology (Berl.) 184, 382-390. doi:10.1007/s00213-005-0125-1

Adriani, W., Spijker, S., DerocheGamonet, V., Laviola, G., Le Moal, M., Smit, A. B., et al. (2003). Evidence for enhanced neurobehavioral vulnerability to nicotine during periadolescence in rats. J. Neurosci. 23, 4712-4716.

Ahmed, S. H., Kenny, P. J., Koob, G. F., and Markou, A. (2002). Neurobiological evidence for hedonic allostasis associated with escalating cocaine use. Nat. Neurosci. 5, 625-626.

Ahmed, S. H., and Koob, G. F. (1998). Transition from moderate to excessive drug

negative affective symptoms) and the escalation of nicotine self-administration will need to be explored, and the possibility that manipulation of CRF and other stress and anti-stress systems can block the escalation of nicotine intake should be examined.

\section{SUMMARY AND CONCLUSION}

Animal models of the acute effects of nicotine have provided us with ample evidence regarding the reinforcing and affective effects of nicotine and neurobiological processes that mediate them. These studies support a central role for the mesocorticolimbic dopamine system and neuronal circuits that interact with it in the acute reinforcing effects of nicotine. Studies using chronic passive delivery of nicotine via intracranial or intraperitoneal routes of administration have provided evidence that chronic nicotine dysregulates nAChRs and downregulates the same neurobiological mechanisms that are involved in the positive reinforcing effects of the drug. However, most of these studies did not examine the relationships between these neurobiological alterations and motivation to consume nicotine after dependence developed. Human smokers tend to begin smoking intermittently, especially at early ages, and quickly develop initial aversive symptoms of abstinence. Their smoking behavior escalates until daily smoking reaches a stable high level that is considered compulsive. Novel models of escalated nicotine intake will allow investigation of the mechanisms that underlie the development of compulsive nicotine intake in rats. Initial evidence suggests that recruitment of brain stress systems is a key factor in this process, but further research is needed. Novel models of nicotine exposure that utilize inhalation also provide a unique opportunity to evaluate the effects of e-cigarette use and second-hand smoking exposure on the vulnerability to dependence and relapse.

\section{ACKNOWLEDGMENTS}

This is publication number 23025 from The Scripps Research Institute. This work was supported by National Institutes of Health Grant DA023597 from the National Institute on Drug Abuse and the Pearson Center for Alcoholism and Addiction Research. The authors would like to thank Michael Arends for his help with manuscript preparation.

intake: change in hedonic set point. Science 282, 298-300. doi:10.1126/science.282.5 387.298

Ahmed, S. H., and Koob, G. F. (1999) Long-lasting increase in the set point for cocaine self-administration after escalation in rats. Psychopharmacology (Berl.) 146, 303-312. doi:10.1007/s002130051121

Ahmed, S. H., Walker, J. R., and Koob, G. F. (2000). Persistent increase in the motivation to take heroin in rats with a history of drug escalation. Neuropsychopharmacology 22, 413-421. doi:10.1016/S0893133X(99)00133-5

Ajzen, I., and Fishbein, M. (1980). Understanding Attitudes and
Predicting Social Behavior Englewood Cliffs, NJ: Prentice Hall.

Alderson, H. L., Latimer, M. P., and Winn, P. (2006). Intravenous self-administration of nicotine is altered by lesions of the posterior, but not anterior, pedunculopontine tegmental nucleus. Eur. J. Neurosci. 23, 2169-2175. doi:10.1111/j.14609568.2006.04737.x

Anderson, K. L., Pinkerton, K. E., Uyeminami, D., Simons, C. T., Carstens, M. I., and Carstens, E. (2004). Antinociception induced by chronic exposure of rats to cigarette smoke. Neurosci. Lett. 366, 86-91. doi:10.1016/j.neulet.2004. 05.020 
Armitage, A. K., Dollery, C. T., George, C. F., Houseman, T. H., Lewis, P. J., and Turner, D. M. (1975). Absorption and metabolism of nicotine from cigarettes. Br. Med. J. 4, 313-316. doi:10.1136/bmj.4.5992.313

Ashby, C. R. Jr., Paul, M., Gardner, E. L., Gerasimov, M. R., Dewey, S. L., Lennon, I. C., et al. (2002). Systemic administration of 1R,4S- 4-amino-cyclopent2-ene-carboxylic acid, a reversible inhibitor of GABA transaminase, blocks expression of conditioned place preference to cocaine and nicotine in rats. Synapse 44, 61-63. doi:10.1002/syn.10052

Ashton, H., and Watson, D. W. (1970). Puffing frequency and nicotine intake in cigarette smokers. Br. Med. J. 3, 679-681. doi:10.1136/bmj.3.5724.679

Audrain-McGovern, J., Al Koudsi, N., Rodriguez, D., Wileyto, E. P., Shields, P. G., and Tyndale, R. F. (2007). The Role of CYP2A6 in the emergence of nicotine dependence in adolescents. Pediatrics 119, 264-274. doi:10.1542/peds.2006-1583

Aujla, H., Cannarsa, R., Romualdi, P., Ciccocioppo, R., Martin-Fardon, R., and Weiss, F. (2013). Modification of anxiety-like behaviors by nociceptin/orphanin FQ (N/OFQ) and time-dependent changes in N/OFQNOP gene expression following ethanol withdrawal. Addict. Biol. 18, 467-479. doi:10.1111/j.13691600.2012.00466.x

Aujla, H., Martin-Fardon, R., and Weiss, F. (2008). Rats with extended access to cocaine exhibit increased stress reactivity and sensitivity to the anxiolytic-like effects of the mGluR 2/3 agonist LY379268 during abstinence. Neuropsychopharmacology 33, 1818-1826. doi:10.1038/sj.npp.1301588

Aydin, C., Oztan, O., and Isgor, C. (2011). Vulnerability to nicotine abstinence-related social anxiety-like behavior: molecular correlates in neuropeptide Y, Y2. Neurosci. Lett. 490, 220-225. doi:10.1016/j.neulet.2010.12.056

Baldo, B. A., Daniel, R. A., Berridge, C. W., and Kelley, A. E. (2003). Overlapping distributions of orexin/hypocretin and dopaminebeta-hydroxylase immunoreactive fibers in rat brain regions mediating arousal, motivation, and stress. J. Comp. Neurol. 464, 220-237. doi:10.1002/cne.10783

Bale, T. L., and Vale, W. W. (2004). $\mathrm{CRF}$ and CRF receptors: role in stress responsivity and other behaviors. Annu. Rev. Pharmacol. Toxicol. 44, 525-557. doi:10.1146/annurev.pharmtox.44. 101802.121410

Balerio, G. N., Aso, E., Berrendero, F., Murtra, P., and Maldonado, R. (2004). Delta9tetrahydrocannabinol decreases somatic and motivational manifestations of nicotine withdrawal in mice. Eur. J. Neurosci. 20, 2737-2748. doi:10.1111/j.14609568.2004.03714.x

Becker, H. C., and Baros, A. M. (2006). Effect of duration and pattern of chronic ethanol exposure on tolerance to the discriminative stimulus effects of ethanol in C57BL/6J mice. J. Pharmacol. Exp. Ther. 319, 871-878. doi:10.1124/jpet.106.108795

Becklake, M. R., Ghezzo, H., and Ernst, P. (2005). Childhood predictors of smoking in adolescence: a follow-up study of Montréal schoolchildren. Can. Med. Assoc. J. 173, 377-379. doi:10.1503/cmaj.1041428

Bélanger, M., O’Loughlin, J., Okoli, C. T., McGrath, J. J., Setia, M., and Guyon, L. (2008). Nicotine dependence symptoms among young never-smokers exposed to secondhand tobacco smoke. Addict. Behav. 33, 1557-1563. doi:10.1016/j.addbeh.2008.07.011

Belluzzi, J. D., Lee, A. G., Oliff, H. S., and Leslie, F. M. (2004). Agedependent effects of nicotine on locomotor activity and conditioned place preference in rats. Psychopharmacology (Berl.) 174, 389-395. doi:10.1007/s00213-003-1758-6

Belluzzi, J. D., Wang, R., and Leslie, F. M. (2005). Acetaldehyde enhances acquisition of nicotine self-administration in adolescent rats. Neuropsychopharmacology 30, 705-712. doi:10.1038/sj.npp.1300586

Benowitz, N. L. (1986). Clinical pharmacology of nicotine. Annu. Rev. Med. 37, 21-32. doi:10.1146/annurev.me.37.020186. 000321

Benowitz, N. L. (1990). Pharmacokinetic considerations in understanding nicotine dependence. Ciba Found. Symp. 152, 186-200.

Benowitz, N. L., and Jacob, P. III. (1984). Daily intake of nicotine during cigarette smoking. Clin. Pharmacol. Ther. 35, 499-504. doi:10.1038/clpt.1984.67

Benowitz, N. L., Kuyt, F., and Jacob, P. III. (1982). Circadian blood nicotine concentrations during cigarette smoking. Clin. Pharmacol. Ther. 32, 758-764. doi:10.1038/clpt.1982.233
Benowitz, N. L., Porchet, H., Sheiner, L., and Jacob, P. III. (1988). Nicotine absorption and cardiovascular effects with smokeless tobacco use: comparison with cigarettes and nicotine gum. Clin. Pharmacol. Ther. 44, 23-28. doi:10.1038/clpt.1988.107

Ben-Shahar, O., Ahmed, S. H., Koob, G. F., and Ettenberg, A. (2004). The transition from controlled to compulsive drug use is associated with a loss of sensitization. Brain Res. 995, 46-54. doi:10.1016/j.brainres.2003.09.053

Benwell, M. E., and Balfour, D. J. (1979). Effects of nicotine administration and its withdrawal on plasma corticosterone and brain 5-hydroxyindoles. Psychopharmacology (Berl.) 63, 7-11. doi:10.1007/BF00426913

Benwell, M. E., Balfour, D. J., and Anderson, J. M. (1990). Smoking-associated changes in the serotonergic systems of discrete regions of human brain. Psychopharmacology (Berl.) 102, 68-72. doi:10.1007/BF02245746

Berlin, I., and Anthenelli, R. M. (2001) Monoamine oxidases and tobacco smoking. Int. J. Neuropsychopharmacol. 4, 33-42.

Berrendero, F., Kieffer, B. L., and Maldonado, R. (2002). Attenuation of nicotine-induced antinociception, rewarding effects, and dependence in mu-opioid receptor knock-out mice. J. Neurosci. 22, 10935-10940.

Berrendero, F., Mendizabal, V., Robledo, P., Galeote, L., Bilkei-Gorzo, A., Zimmer, A., et al. (2005). Nicotine-induced antinociception, rewarding effects, and physical dependence are decreased in mice lacking the preproenkephalin gene. J. Neurosci. 25, 1103-1112. doi:10.1523/JNEUROSCI.300804.2005

Berrendero, F., Robledo, P., Trigo, J. M., Martín-García, E., and Maldonado, R. (2010). Neurobiological mechanisms involved in nicotine dependence and reward: participation of the endogenous opioid system. Neurosci. Biobehav. Rev. 35, 220-231. doi:10.1016/j.neubiorev.2010.02.006

Bespalov, A., Lebedev, A., Panchenko, G., and Zvartau, E. (1999). Effects of abused drugs on thresholds and breaking points of intracranial self-stimulation in rats. Eur. Neuropsychopharmacol. 9, 377-383. doi:10.1016/ S0924-977X(99)00008-5

Bhattacharyya, N. (2012). Trends in the use of smokeless tobacco in United
States, 2000-2010. Laryngoscope 122, 2175-2178. doi:10.1002/lary.23448

Biala, G., and Budzynska, B. (2006). Effects of acute and chronic nicotine on elevated plus maze in mice: involvement of calcium channels. Life Sci. 30, 81-88. doi:10.1016/j.lfs.2005.12.043

Biala, G., Budzynska, B., and Kruk, M. (2005). Naloxone precipitates nicotine abstinence syndrome and attenuates nicotine-induced antinociception in mice. Pharmacol. Rep. 57, 755-760.

Bozarth, M. A., Pudiak, C. M., and KuoLee, R. (1998a). Effect of chronic nicotine on brain stimulation reward. II. An escalating dose regimen. Behav. Brain Res. 96, 189-194. doi:10. 1016/S0166-4328(98)00050-3

Bozarth, M. A., Pudiak, C. M. and KuoLee, R. (1998b). Effect of chronic nicotine on brain stimulation reward. I. Effect of daily injections. Behav. Brain Res. 96, 185-188. doi:10.1016/S01664328(98)00050-3

O’Dell, L. E., Torres, O. V., Natividad, L. A., and Tejeda, H. A. (2007). Adolescent nicotine exposure produces less affective measures of withdrawal relative to adult nicotine exposure in male rats. Neurotoxicol. Teratol. 29, 17-22. doi:10.1016/j.ntt.2006.11.003

Brioni, J. D., O’Neill, A. B., Kim, D. J. B., and Decker, M. W. (1993). Nicotinic receptor agonists exhibit anxiolyticlike effects on the elevated plus-maze test. Eur. J. Pharmacol. 283, 1-8. doi:10.1016/0014-2999(93)90498-7

Brody, A. L., Mandelkern, M. A., London, E. D., Khan, A., Kozman, D., Costello, M. R., et al. (2011). Effect of secondhand smoke on occupancy of nicotinic acetylcholine receptors in brain. Arch. Gen. Psychiatry 68, 953-960. doi:10.1001/ archgenpsychiatry.2011.51

Brody, A. L., Mandelkern, M. A., London, E. D., Olmstead, R. E., Farahi, J., Scheibal, D., et al. (2006). Cigarette smoking saturates brain alpha 4 beta 2 nicotinic acetylcholine receptors. Arch. Gen. Psychiatry 63, 907-915. doi:10.1001/archpsyc.63.8.907

Brook, J. S., Saar, N. S., Zhang, C., and Brook, D. W. (2009). Familial and non-familial smoking: effects on smoking and nicotine dependence. Drug Alcohol Depend. 101, 62-68. doi:10.1016/j.drugalcdep. 2008.11.003

Broqua, P., Wettstein, J. G., Rocher, M. N., Gauthier-Martin, B., and Junien, J. L. (1995). Behavioral effects of neuropeptide $\mathrm{Y}$ receptor 
agonists in the elevated plusmaze and fear-potentiated startle procedures. Behav. Pharmacol. 6, 215-222. doi:10.1097/00008877199504000-00001

Bruijnzeel, A. W. (2012). Tobacco addiction and the dysregulation of brain stress systems. Neurosci. Biobehav. Rev. 36, 1418-1441. doi:10.1016/j.neubiorev.2012.02.015

Bruijnzeel, A. W., Bishnoi, M., Van Tuijl, I. A., Keijzers, K. F., Yavarovich, K. R., Pasek, T. M., et al. (2010). Effects of prazosin, clonidine, and propranolol on the elevations in brain reward thresholds and somatic signs associated with nicotine withdrawal in rats. Psychopharmacology (Berl.) 212, 485-499. doi:10.1007/s00213010-1970-0

Bruijnzeel, A. W., Prado, M., and Isaac, S. (2009). Corticotropin-releasing factor-1 receptor activation mediates nicotine withdrawal-induced deficit in brain reward function and stress-induced relapse. Biol. Psychiatry 66, 110-117. doi:10.1016/j.biopsych.2009.01.010

Bullen, C., McRobbie, H., Thornley, S., Glover, M., Lin, R., and Laugesen, M. (2010). Effect of an electronic nicotine delivery device (e cigarette) on desire to smoke and withdrawal, user preferences and nicotine delivery: randomised crossover trial. Tob. Control 19, 98-103. doi:10.1136/tc.2009.031567

Cahn, Z., and Siegel, M. (2011). Electronic cigarettes as a harm reduction strategy for tobacco control: a step forward or a repeat of past mistakes? J. Public Health Policy 32, 16-31. doi:10.1057/jphp.2010.41

Caponnetto, P., Campagna, D., Papale, G., Russo, C., and Polosa, R. (2012). The emerging phenomenon of electronic cigarettes. Expert. Rev. Respir. Med. 6, 63-74. doi:10.1586/ers. 11.92

Carr, G. D., Fibiger, H. C., and Phillips, A. G. (1989). "Conditioned place preference as a measure of drug reward," in Neuropharmacological Basis of Reward, eds J. M. Liebman and S. J. Cooper (New York: Oxford University Press), 264-319.

Carroll, M. E., Lac, S. T., Asencio, M., and Keenan, R. M. (1989). Nicotine dependence in rats. Life Sci. 45, 1381-1388. doi:10.1016/00243205(89)90025-8

Changeux, J. P., Devillers-Thiery, A., and Chemouilli, P. (1984). Acetylcholine receptor: an allosteric protein. Science 225, 1335-1345. doi:10.1126/science.6382611

Chaudhri, N., Caggiula, A. R., Donny, E. C., Palmatier, M. I., Liu, X., and Sved,
A. F. (2006). Complex interactions between nicotine and nonpharmacological stimuli reveal multiple roles for nicotine in reinforcement. Psychopharmacology (Berl.) 184, 353-366. doi:10.1007/s00213005-0178-1

Cheeta, S., Irvine, E., and File, S. E. (2001). Social isolation modifies nicotine's effects in animal tests of anxiety. $\mathrm{Br} . \mathrm{J}$. Pharmacol. 132, 1389-1395. doi:10.1038/sj.bjp.0703991

Chen, H., Fu, Y., and Sharp, B. M. (2008). Chronic nicotine self-administration augments hypothalamic-pituitary-adrenal responses to mild acute stress. $\mathrm{Neu}$ ropsychopharmacology 33, 721-730. doi:10.1038/sj.npp.1301466

Chen, H., Matta, S. G., and Sharp, B. M. (2007). Acquisition of nicotine self-administration in adolescent rats given prolonged access to the drug. Neuropsychopharmacology 32, 700-709. doi:10.1038/sj.npp.1301135

Ciccocioppo, R., Fedeli, A., Economidou, D., Policani, F., Weiss, F., and Massi, M. (2003). corticotropinreleasing factor and for its reversal by nociceptin/orphanin FQ. J. Neurosci. 23, 9445-9451.

Cippitelli, A., Astarita, G., Duranti, A., Caprioli, G., Ubaldi, M., Stopponi, S., et al. (2011). Endocannabinoid regulation of acute and protracted nicotine withdrawal: effect of FAAH inhibition. PLOS ONE 6:e28142. doi:10.1371/journal.pone.0028142

Clarke, P. B., and Fibiger, H. C. (1987). Apparent absence of nicotine-induced conditioned place preference in rats. Psychopharmacology (Berl.) 92, 84-88. doi:10.1007/BF00215484

Clarke, P. B., Fu, D. S., Jakubovic, A., and Fibiger, H. C. (1988). Evidence that mesolimbic dopaminergic activation underlies the locomotor stimulant action of nicotine in rats. J. Pharmacol. Exp. Ther. 246, 701-708.

Clarke, P. B., and Kumar, R. (1983). The effects of nicotine on locomotor activity in non-tolerant and tolerant rats. Br. J. Pharmacol. 78, 329-337. doi:10.1111/j.14765381.1983.tb09398.x

Clarke, P. B., and Kumar, R. (1984). Some effects of nicotine on food and water intake in undeprived rats. Br. J. Pharmacol. 82, 233-239. doi:10.1111/j.14765381.1984.tb16463.x

Clarke, P. B. S., and Reuben, M. (1996). Release of $[3 \mathrm{H}]$-noradrenaline from rat hippocampal synaptosomes by nicotine: mediation by different nicotinic receptor subtypes from striatal $[3 \mathrm{H}]$-dopamine release. Br. J. Pharmacol. 117, 595-606. doi:10.1111/j.14765381.1996.tb15232.x

Clemens, K. J., Caillé, S., Stinus, L., and Cador, M. (2009). The addition of five minor tobacco alkaloids increases nicotine-induced hyperactivity, sensitization and intravenous self-administration in rats. Int. J. Neuropsychopharmacol. 12, 1355-1366. doi:10.1017/S1461145709000273

Coggins, C. R. (2007). An updated review of inhalation studies with cigarette smoke in laboratory animals. Int. J. Toxicol. 26, 331-338. doi:10.1080/10915810701490190

Coggins, C. R., Murrelle, E. L., Carchman, R. A., and Heidbreder, C. (2009). Light and intermittent cigarette smokers: a review (19892009). Psychopharmacology (Berl.) 207, 343-363. doi:10.1007/s00213009-1675-4

Cohen, A., Koob, G. F., and George, O. (2012). Robust escalation of nicotine intake with extended access to nicotine selfadministration and intermittent periods of abstinence. Neuropsychopharmacology 37, 2153-2160. doi:10.1038/npp.2012.67

Cohen, C., Perrault, G., Voltz, C. Steinberg, R., and Soubrie, P. (2002). SR141716, a central cannabinoid $(\mathrm{CB}(1))$ receptor antagonist, blocks the motivational and dopamine-releasing effects of nicotine in rats. Behav. Pharmacol. 13, 451-463. doi:10.1097/00008877200209000-00018

Collins, A. C., Bhat, R. V., Pauly, J. R., and Marks, M. J. (1990). Modulation of nicotine receptors by chronic exposure to nicotinic agonists and antagonists. Ciba Found. Symp. 152, 68-82.

Collins, A. C., Luo, Y., Selvaag, S., and Marks, M. J. (1994). Sensitivity to nicotine and brain nicotinic receptors are altered by chronic nicotine and mecamylamine infusion. $J$. Pharmacol. Exp. Ther. 271, 125-133.

Collins, A. C., Romm, E., and Wehner, J. M. (1988). Nicotine tolerance: an analysis of the time course of its development and loss in the rat. Psychopharmacology (Berl.) 96, 7-14. doi:10.1007/BF02431526

Coppen, A. (1967). The biochemistry of affective disorders. $\mathrm{Br}$. J. Psychiatry 113, 1237-1264. doi:10.1192/bjp.113.504.1237

Corrigall, W. A. (2009). Hypocretin mechanisms in nicotine addiction: evidence and speculation. Psychopharmacology (Berl.) 206, 23-37. doi:10.1007/s00213-009-1588-2

Corrigall, W. A., and Coen, K. M. (1989). Nicotine maintains robust self-administration in rats on a limited-access schedule. Psychopharmacology (Berl.) 99, 473-478. doi:10.1007/BF00589894

Corrigall, W. A., and Coen, K. M. (1991). Opiate antagonists reduce cocaine but not nicotine self-administration. Psychopharmacology (Berl.) 104, 167-170. doi:10.1007/BF02244174

Corrigall, W. A., Coen, K. M., and Adamson, K. L. (1994). Selfadministered nicotine activates the mesolimbic dopamine system through the ventral tegmental area. Brain Res. 653, 278-284. doi:10.1016/0006-8993(94)90401-4

Corrigall, W. A., Coen, K. M., Adamson, K. L., Chow, B. L., and Zhang, J. (2000). Response of nicotine selfadministration in the rat to manipulations of mu-opioid and gammaaminobutyric acid receptors in the ventral tegmental area. Psychopharmacology (Berl.) 149, 107-114. doi:10.1007/s002139900355

Corrigall, W. A., Coen, K. M., Zhang, J., and Adamson, K. L. (2001). GABA mechanisms in the pedunculopontine tegmental nucleus influence particular aspects of nicotine self-administration selectively in the rat. Psychopharmacology (Berl.) 158, 190-197. doi:10.1007/s002130100869

Corrigall, W. A., Coen, K. M., Zhang, J., and Adamson, L. (2002). Pharmacological manipulations of the pedunculopontine tegmental nucleus in the rat reduce selfadministration of both nicotine and cocaine. Psychopharmacology (Berl.) 160, 198-205. doi:10.1007/s00213-001-0965-2

Cox, B. M., Goldstein, A., and Nelson, W. T. (1984). Nicotine self-administration in rats. Br. J. Pharmacol. 83, 49-55. doi:10.1111/j.14765381.1984.tb10118.x

Craft, R. M., and Milholland, R. B. (1998). Sex differences in cocaineand nicotine-induced antinociception in the rat. Brain Res. 809, 137-140. doi:10.1016/S00068993(98)00841-5

Crombag, H. S., Ferrario, C. R., and Robinson, T. E. (2008). The rate of intravenous cocaine or amphetamine delivery does not influence drug-taking and drugseeking behavior in rats. Pharmacol. Biochem. Behav. 90, 797-804. doi:10.1016/j.pbb 
Cryan, J. F., Bruijnzeel, A. W., Skjei, K. L., and Markou, A. (2003). Bupropion enhances brain reward function and reverses the affective and somatic aspects of nicotine withdrawal in the rat. Psychopharmacology (Berl.) 168, 347-358. doi:10.1007/s00213003-1445-7

Cummings, K. M., and Mahoney, M. (2006). Current and emerging treatment approaches for tobacco dependence. Curr. Oncol. Rep. 8, 475-483. doi:10.1007/s11912-006-0077-6

Dal Cin, S., Stoolmiller, M., and Sargent, J. D. (2012). When movies matter: exposure to smoking in movies and changes in smoking behavior. J. Health Commun. 17, 76-89. doi:10.1080/10810730.2011.585697

Damaj, M. I. (2000). The involvement of spinal $\mathrm{Ca} 2+/$ calmodulinprotein kinase II in nicotine-induced antinociception in mice. Eur. J. Pharmacol. 404, 103-110. doi:10. 1016/S0014-2999(00)00579-3

Damaj, M. I., Kao, W., and Martin, B. R. (2003). Characterization of spontaneous and precipitated nicotine withdrawal in the mouse. J. Pharmacol. Exp. Ther. 307, 526-534. doi:10.1124/jpet.103.054908

Damaj, M. I., Welch, S. P., and Martin, B. R. (1994). Nicotine-induced antinociception in mice: role of Gproteins and adenylate cyclase. Pharmacol. Biochem. Behav. 48, 37-42. doi:10.1016/0091-3057(94)90494-4

Dani, J. A. (2001). Nicotinic receptor activity alters synaptic plasticity. ScientificWorldJournal 1, 393-395. doi:10.1100/tsw.2001.74

Dani, J. A., and Bertrand, D. (2007). Nicotinic acetylcholine receptors and nicotinic cholinergic mechanisms of the central nervous system. Annu. Rev. Pharmacol. Toxicol. 47, 699-729. doi:10.1146/annurev. pharmtox.47.120505.105214

Dani, J. A., and Heinemann, S. (1996). Molecular and cellular aspects of nicotine abuse. Neuron 16, 905-908. doi:10.1016/S08966273(00)80112-9

Deak, T., Nguyen, T., Ehrlich, A. L., Watkins, L. R., Spencer, R. L., Maier, S. F., et al. (1999). The impact of the nonpeptide corticotropin-releasing hormone antagonist antalarmin on behavioral and endocrine responses to stress. Endocrinology 140, 79-86. doi:10.1210/en.140.1.79

DeNoble, V. J., and Mele, P. C. (2006). Intravenous nicotine selfadministration in rats: effects of mecamylamine, hexamethonium and naloxone. Psychopharmacology (Berl.) 184, 266-272. doi:10.1007/ s00213-005-0054-Z von der Goltz, C., Koopmann, A., Dinter, C., Richter, A., Rockenbach, C., Grosshans, M., et al. (2010). Orexin and leptin are associated with nicotine craving: a link between smoking, appetite and reward. Psychoneuroendocrinology 35, 570-577. doi:10.1016/j.psyneuen.2009.09.005

Dhatt, R. K., Gudehithlu, K. P., Wemlinger, T. A., Tejwani, G. A., Neff, N. H., and Hadjiconstantinou, M. (1995). Preproenkephalin mRNA and methionine-enkephalin content are increased in mouse striatum after treatment with nicotine. J. Neurochem. 64, 1878-1883. doi:10.1046/j.14714159.1995.64041878.x

Di Chiara, G. (2000). Role of dopamine in the behavioural actions of nicotine related to addiction. Eur. J. Pharmacol. 393, 295-314. doi:10.1016/ S0014-2999(00)00122-9

Dierker, L., and Mermelstein, R. (2010). Early emerging nicotinedependence symptoms: a signal of propensity for chronic smoking behavior in adolescents. J. Pediatr. 156, 818-822. doi:10.1016/j.jpeds.2009.11.044

DiFranza, J. R., Savageau, J. A., Fletcher, K., O'Loughlin, J., Pbert, L., Ockene, J. K., et al. (2007). Symptoms of tobacco dependence after brief intermittent use. The development and assessment of nicotine dependence in youth-2 study. Arch. Pediatr. Adolesc. Med. 161, 704-710. doi:10.1001/archpedi. 161.7.704

DiFranza, J. R., Savageau, J. A., Rigotti, N. A., Fletcher, K., Ockene, J. K., McNeill, A. D., et al. (2002). Development of symptoms of tobacco dependence in youths: 30 month follow up data from the DANDY study. Tob. Control 11, 228-235. doi:10.1136/tc.11.3.228

Donny, E. C., Caggiula, A. R., Knopf, S., and Brown, C. (1995). Nicotine selfadministration in rats. Psychopharmacology (Berl.) 122, 390-394. doi:10.1007/BF02246272

Donny, E. C., Caggiula, A. R., Rowell, P. P., Gharib, M. A., Maldovan, V., Booth, S., et al. (2000). Nicotine selfadministration in rats: estrous cycle effects, sex differences and nicotinic receptor binding. Psychopharmacology (Berl.) 151, 392-405. doi:10.1007/s002130000497

Doubeni, C. A., Reed, G., and Difranza, J. R. (2010). Early course of nicotine dependence in adolescent smokers. Pediatrics 125, 1127-1133. doi:10.1542/peds.2009-0238

Dozois, D. N., Farrow, J. A., and Miser, A. (1995). Smoking patterns and cessation motivations during adolescence. Int. J. Addict. 30, 1485-1498.

Dunn, A. J., and Berridge, C. W. (1990). Physiological and behavioral responses to corticotropin-releasing factor administration: is CRF a mediator of anxiety or stress responses? Brain Res. Rev. 15, 71-100. doi:10.1016/0165-0173(90)90012-D

Dworkin, S. I., Mirkis, S., and Smith, J. E. (1995). Response-dependent versus response-independent presentation of cocaine: differences in the lethal effects of the drug. Psychopharmacology (Berl.) 117, 262-266. doi:10.1007/BF02246100

Dwoskin, L. P., Crooks, P. A., Teng, L., Green, T. A., and Bardo, M. T. (1999). Acute and chronic effects of nornicotine on locomotor activity in rats: altered response to nicotine. Psychopharmacology (Berl.) 145, 442-451. doi:10.1007/s002130051079

Economidou, D., Cippitelli, A., Stopponi, S., Braconi, S., Clementi, S., Ubaldi, M., et al. (2011). Activation of brain NOP receptors attenuates acute and protracted alcohol withdrawal symptoms in the rat. Alcohol. Clin. Exp. Res. 35, 747-755. doi:10.1111/j.15300277.2010.01392.x

Epping-Jordan, M. P., Watkins, S. S., Koob, G. F., and Markou, A. (1998). Dramatic decreases in brain reward function during nicotine withdrawal. Nature 393, 76-79. doi:10.1038/30001

Etter, J. F. (2012). Commentary on Wagener et al. (2012): electronic cigarettes - the Holy Grail of nicotine replacement? Addiction 107, 1550-1552. doi:10.1111/j.13600443.2012.03909.x

Etter, J. F., and Bullen, C. (2011). Electronic cigarette: users profile, utilization, satisfaction and perceived efficacy. Addiction 106, 2017-2028. doi:10.1111/j.13600443.2011.03505.x

Farkas, S., Hussein, J., Ariano, R. E. Sitar, D. S., and Hasan, S. U. (2006). Prenatal cigarette smoke exposure: pregnancy outcome and gestational changes in plasma nicotine concentration, hematocrit, and carboxyhemoglobin in a newly standardized rat model. Toxicol. Appl. Pharmacol. 214, 118-125. doi:10.1016/j.taap.2005.12.010

Fellows, J. L., Trosclair, A., and Adams, E. K. (2002). Annual smokingattributable mortality, years of potential life lost, and economic costs: United States, 1995-1999.
MMWR Morb. Mortal. Wkly. Rep. 51, 300-303.

Fenster, C. P., Whitworth, T. L., Sheffield, E. B., Quick, M. W., and Lester, R. A. (1999). Upregulation of surface alpha4beta2 nicotinic receptors is initiated by receptor desensitization after chronic exposure to nicotine. $J$. Neurosci. 19, 4804-4814.

Ford, R. D., and Balster, R. (1976). Schedule-controlled behavior in the morphine-dependent rat. Pharmacol. Biochem. Behav. 4, 569-573. doi:10.1016/0091-3057(76)90199-4

Fowler, C. D., Lu, Q., Johnson, P. M., Marks, M. J., and Kenny, P. J. (2011). Habenular a5 nicotinic receptor subunit signalling controls nicotine intake. Nature 471, 597-601. doi:10.1038/nature09797

Fowler, J. S., Logan, J., Wang, G. J., Volkow, N. D., Telang, F. Zhu, W., et al. (2003). Low monoamine oxidase $\mathrm{B}$ in peripheral organs in smokers. Proc. Natl. Acad. Sci. U.S.A. 100, 11600-11605. doi:10.1073/pnas.1833106100

Fu, Y., Matta, S. G., Gao, W., Brower, V. G., and Sharp, B. M. (2000). Systemic nicotine stimulates dopamine release in nucleus accumbens: reevaluation of the role of N-methyl$D$-aspartate receptors in the ventral tegmental area. J. Pharmacol. Exp. Ther. 294, 458-465.

Fudala, P. J., Teoh, K. W., and Iwamoto, E. T. (1985). Pharmacologic characterization of nicotine-induced conditioned place preference. Pharmacol. Biochem. Behav. 22, 237-241. doi:10.1016/0091-3057(85)90384-3

Fuller, B. F., Cortes, D. F., Landis, M. K., Yohannes, H., Griffin, H. E., Stafflinger, J. E., et al. (2012). Exposure of rats to environmental tobacco smoke during cerebellar development alters behavior and perturbs mitochondrial energetics. Environ. Health Perspect. 120, 1684-1691. doi:10.1289/ehp.1104857

Fuller, B. F., Gold, M. S., Wang, K. K., and Ottens, A. K. (2010). Effects of environmental tobacco smoke on adult rat brain biochemistry. J. Mol. Neurosci. 41, 165-171. doi:10.1007/s12031-009-9316-2

Fung, Y. K., Schmid, M. J., Anderson, T. M., and Lau, Y. S. (1996). Effects of nicotine withdrawal on central dopaminergic systems. Pharmacol. Biochem. Behav. 53, 635-640. doi:10.1016/00913057(95)02063-2

Galeote, L., Berrendero, F., Bura, S. A., Zimmer, A., and Maldonado, R. (2009). Prodynorphin gene disruption increases the sensitivity 
to nicotine self-administration in mice. Int. J. Neuropsychopharmacol. 12, 615-625. doi:10.1017/S1461145708009450

Galeote, L., Kieffer, B. L., Maldonado, R., and Berrendero, F. (2006). Mu-opioid receptors are involved in the tolerance to nicotine antinociception. J. Neurochem. 97, 416-423. doi:10.1111/j.14714159.2006.03751.x

George, O., Ghozland, S., Azar, M. R., Cottone, P., Zorrilla, E. P., Parsons, L. H., et al. (2007). CRF-CRF1 system activation mediates withdrawal-induced increases in nicotine self-administration in nicotine-dependent rats. Proc. Natl. Acad. Sci. U.S.A. 104, 17198-17203. doi:10.1073/pnas.0707585104

George, O., Grieder, T. E., Cole, M., and Koob, G. F. (2010). Exposure to chronic intermittent nicotine vapor induces nicotine dependence. Pharmacol. Biochem. Behav. 96, 104-107. doi:10.1016/j.pbb.2010.04.013

Gervais, A., O’Loughlin, J., Dugas, E., Eisenberg, M. J., Wellman, R. J., and DiFranza, J. R. (2007). A systematic review of randomized controlled trials of youth smoking cessation interventions. Drogues, santá et société 6(Suppl. 2):ii1-ii26.

Gilpin, N. W., Whitaker, A. M., Baynes, B., Abdel, A. Y., Weil, M. T., and George, O. (2013). Nicotine vapor inhalation escalates nicotine self-administration. Addict. Biol. doi:10.1111/adb.12021. [Epub ahead of print].

Ginzel, K. H., and Eldred, E. (1977). "Reflex depression of somatic motor activity from heart, lungs and carotid sinus," in Krogh Centenary Symposium on Respiratory Adaptation, Capillary Exchange and Reflex Mechanisms, eds A. S. Paintal and P. Gill-Kumar (Delhi: Vallabhbhai Patel Chest Institute, University of Delhi), 358-395.

Giovino, G. A., Mirza, S. A., Samet, J. M., Gupta, P. C., Jarvis, M. J., Bhala, N., et al. (2012). GATS Collaborative Group. Tobacco use in 3 billion individuals from 16 countries: an analysis of nationally representative crosssectional household surveys. Lancet 380, 668-679. doi:10.1016/S01406736(12)61085-X

Girod, R., and Role, L. W. (2001). Longlasting enhancement of glutamatergic synaptic transmission by acetylcholine contrasts with response adaptation after exposure to lowlevel nicotine. J. Neurosci. 21, 5182-5190.

Göktalay, G., Cavun, S., Levendusky, M. C., Hamilton, J. R., and
Millington, W. R. (2006). Glycylglutamine inhibits nicotine conditioned place preference and withdrawal. Eur. J. Pharmacol. 530, 95-102. doi:10.1016/j.ejphar.2005. 11.034

Golub, M. S., Slotkin, T. A., Tarantal, A. F., and Pinkerton, K. E. (2007). Visual recognition memory and auditory brainstem response in infant rhesus monkeys exposed perinatally to environmental tobacco smoke. Brain Res. 2, 102-106.

Goniewicz, M. L., Kuma, T., Gawron, M., Knysak, J., and Kosmider, L. (2013). Nicotine levels in electronic cigarettes. Nicotine Tob. Res. 15, 158-166. doi:10.1093/ntr/nts103

Gourlay, S. G., Stead, L. F., and Benowitz, N. L. (2004). Clonidine for smoking cessation. Cochrane Database Syst. Rev. 2004:CD000058. doi:10.1002/14651858.CD000058. pub2

Grabus, S. D., Martin, B. R., Batman, A. M., Tyndale, R. F., Sellers, E., and Damaj, M. I. (2005). Nicotine physical dependence and tolerance in the mouse following chronic oral administration. Psychopharmacology (Berl.) 178, 183-192. doi:10.1007/s00213-004-2007-3

Greenwell, T. N., Funk, C. K., Cottone, P., Richardson, H. N., Chen, S. A., Rice, K. C., et al. (2009). Corticotropin-releasing factor-1 receptor antagonists decrease heroin self-administration in long-but not short-access rats. Addict. Biol. 14, 130-143. doi:10.1111/j.13691600.2008.00142.x

Griebel, G., Perrault, G., and Sanger, D. J. (1998). Characterization of the behavioral profile of the nonpeptide CRF receptor antagonist CP-154,526 in anxiety models in rodents. Comparison with diazepam and buspirone. Psychopharmacology (Berl.) 138, 55-66. doi:10.1007/s002130050645

Grieder, T. E., George, O., Tan, H., George, S. R., Le Foll, B., Laviolette, S. R., et al. (2012). Phasic D1 and tonic D2 dopamine receptor signaling double dissociate the motivational effects of acute nicotine and chronic nicotine withdrawal. Proc. Natl. Acad. Sci. U.S.A. 109, 3101-3106. doi:10.1073/pnas.1114422109

Grieder, T. E., Sellings, L. H., VargasPerez, H., Ting-A-Kee, R., Siu, E. C., Tyndale, R. F., et al. (2010). Dopaminergic signaling mediates the motivational response underlying the opponent process to chronic but not acute nicotine. Neuropsychopharmacology 35, 943-954. doi:10.1038/npp. 2009.198
Grillner, P., and Svensson, T. H. (2000). Nicotine-induced excitation of midbrain dopamine neurons in vitro involves ionotropic glutamate receptor activation. Synapse 38, 1-9. doi:10.1002/10982396(200010)38:1<1::AID-

SYN1>3.0.CO;2-A

Grottick, A. J., Corrigall, W. A., and Higgins, G. A. (2001). Activation of $5-\mathrm{HT}(2 \mathrm{C})$ receptors reduces the locomotor and rewarding effects of nicotine. Psychopharmacology (Berl.) 157, 292-298. doi:10.1007/s002130100801

Grunberg, N. E., Bowen, D. J., and Winders, S. E. (1986). Effects of nicotine on body weight and food consumption in female rats. Psychopharmacology (Berl.) 90, 101-105. doi:10.1007/BF00 172879

Guillem, K., Vouillac, C., Azar, M. R., Parsons, L. H., Koob, G. F., Cador, M., et al. (2005). Monoamine oxidase inhibition dramatically increases the motivation to self-administer nicotine in rats. J. Neurosci. 25, 8593-8600. doi:10.1523/JNEUROSCI.213905.2005

Guillem, K., Vouillac, C., Azar, M. R., Parsons, L. H., Koob, G. F., Cador, M., et al. (2006). Monoamine oxidase A rather than monoamine oxidase $\mathrm{B}$ inhibition increases nicotine reinforcement in rats. Eur. J. Neurosci. 24, 3532-3540. doi:10.1111/j.14609568.2006.05217.x

Hanson, H. M., Ivester, C. A., and Morton, B. R. (1979). "Nicotine selfadministration in rats," in Cigarette Smoking as a Dependence Process, ed. N. A. Kraznegor (Rockville, MD: NIDA Res Monogr 23. Alcohol, Drug Abuse and Mental Health Administration), 70-90.

Harris, A. C., Mattson, C., Lesage, M. G., Keyler, D. E., and Pentel, P. R. (2010). Comparison of the behavioral effects of cigarette smoke and pure nicotine in rats. Pharmacol. Biochem. Behav. 96, 217-227. doi:10.1016/j.pbb.2010.05.008

Harris, A. C., Pentel, P. R., Burroughs, D., Staley, M. D., and Lesage, M. G. (2011). A lack of association between severity of nicotine withdrawal and individual differences in compensatory nicotine self-administration in rats. Psychopharmacology (Berl.) 217, 153-166. doi:10.1007/s00213011-2273-9

Harrison, A. A., Gasparini, F., and Markou, A. (2002). Nicotine potentiation of brain stimulation reward reversed by $\mathrm{DH}$ beta $\mathrm{E}$ and $\mathrm{SCH}$
23390, but not by eticlopride, LY 314582 or MPEP in rats. Psychopharmacology (Berl.) 160, 56-66. doi:10.1007/s00213-001-0953-6

Harvey, D. M., Yasar, S., Heishman, S. J., Panlilio, L. V., Henningfield, J. E., and Goldberg, S. R. (2004). Nicotine serves as an effective reinforcer of intravenous drug-taking behavior in human cigarette smokers. Psychopharmacology (Berl.) 175, 134-142. doi:10.1007/s00213-0041818-6

Hayes, D. J., Mosher, T. M., and Greenshaw, A. J. (2009). Differential effects of 5-HT2C receptor activation by WAY 161503 on nicotine-induced place conditioning and locomotor activity in rats. Behav. Brain Res. 197, 323-330. doi:10.1016/j.bbr.2008.08.034

Hecht, S. S. (2005). Carcinogenicity studies of inhaled cigarette smoke in laboratory animals: old and new. Carcinogenesis 26, 1488-1492. doi:10.1093/carcin/bgi148

Heilig, M., and Murison, R. (1987). Intracerebroventricular neuropeptide $\mathrm{Y}$ protects against stress-induced gastric erosion in the rat. Eur. J. Pharmacol. 137, 127-129. doi:10. 1016/0014-2999(87)90191-9

Heimer, L., and Alheid, G. (1991). "Piecing together the puzzle of basal forebrain anatomy," in The Basal Forebrain: Anatomy to Function (Series Title: Advances in Experimental Medicine and Biology, Vol. 295), eds T. C. Napier, P. W. Kalivas, and I. Hanin (New York: Plenum Press), 1-42.

Heinz, A. J., Kassel, J. D., Berbaum, M., and Mermelstein, R. (2010). Adolescents' expectancies for smoking to regulate affect predict smoking behavior and nicotine dependence over time. Drug Alcohol Depend. 111, 128-135. doi:10.1016/j.drugalcdep.2010.04 001

Henningfield, J. E., and Goldberg, S. R. (1983). Nicotine as a reinforcer in human subjects and laboratory animals. Pharmacol. Biochem. Behav. 19, 989-992. doi:10.1016/0091-3057(83)90405-7

Henningfield, J. E., and Keenan, R. M. (1993). Nicotine delivery kinetics and abuse liability. J. Consult. Clin. Psychol. 61, 743-750. doi:10.1037/0022-006X.61.5.743

Hildebrand, B. E., Nomikos, G. G., Hertel, P., Schilström, B., and Svensson, T. H. (1998). Reduced dopamine output in the nucleus accumbens but not in the medial prefrontal cortex in rats displaying 
a mecamylamine-precipitated nicotine withdrawal syndrome. Brain Res. 779, 214-225. doi:10. 1016/S0006-8993(97)01135-9

Hilleman, D. E., Mohiuddin, S. M., Del Core, M. G., and Sketch, M. H. Sr. (1992). Effect of buspirone on withdrawal symptoms associated with smoking cessation. Arch. Intern. Med. 152, 350-352. doi:10.1001/archinte.152.2.350

Hilleman, D. E., Mohiuddin, S. M., and Delcore, M. G. (1994). Comparison of fixed-dose transdermal nicotine, tapered-dose transdermal nicotine, and buspirone in smoking cessation. J. Clin. Pharmacol. 34, 222-224. doi:10.1002/j.15524604.1994.tb03989.x

Hoffman, A. C., and Evans, S. E. (2013). Abuse potential of non-nicotine tobacco smoke components: acetaldehyde, nornicotine, cotinine, and anabasine. Nicotine Tob. Res. 15, 622-632. doi:10.1093/ntr/nts192

Horan, B., Smith, M., Gardner, E. L., Lepore, M., and Ashby, C. R. Jr. (1997). Nicotine produces conditioned place preference in Lewis, but not Fischer 344 rats. Synapse 26, 93-94. doi:10.1002/(SICI)10982396(199705)26:1<93::AID-

SYN10>3.0.CO;2-W

Hughes, J. R. (2007). Effects of abstinence from tobacco: valid symptoms and time course. Nicotine Tob. Res. 9, 315-327. doi:10.1080/14622200701188919

Hughes, J. R., Gust, S. W., Skoog, K., Keenan, R. M., and Fenwick, J. W. (1991). Symptoms of tobacco withdrawal. A replication and extension. Arch. Gen. Psychiatry 48, 52-59. doi:10.1001/archpsyc.1991.0181025 0054007

Huston-Lyons, D., and Kornetsky, C. (1992). Effects of nicotine on the threshold for rewarding brain stimulation in rats. Pharmacol. Biochem. Behav. 41, 755-759. doi:10.1016/0091-3057(92)90223-3

Huston-Lyons, D., Sarkar, M., and Kornetsky, C. (1993). Nicotine and brain-stimulation reward: interactions with morphine, amphetamine and pimozide. Pharmacol. Biochem. Behav. 46, 453-457. doi:10.1016/0091-3057(93)90378-7

Ikemoto, S., Qin, M., and Liu, Z. H. (2006). Primary reinforcing effects of nicotine are triggered from multiple regions both inside and outside the ventral tegmental area. J. Neurosci. 18, 723-730. doi:10. 1523/JNEUROSCI.4542-05.2006

Irvine, E. E., Cheeta, S., and File, S. E. (1999). Time-course of changes in the social interaction test of anxiety following acute and chronic administration of nicotine. Behav. Pharmacol. 10, 691-697. doi:10.1097/00008877-19991100000016

Irvine, E. E., Cheeta, S., Marshall, M. and File, S. E. (2001). Different treatment regimens and the development of tolerance to nicotine's anxiogenic effects. Pharmacol. Biochem. Behav. 68, 769-776. doi:10.1016/S00913057(01)00469-5

Isola, R., Vogelsberg, V., Wemlinger, T. A., Neff, N. H., and Hadjiconstantinou, M. (1999). Nicotine abstinence in the mouse. Brain Res. 850, 189-196. doi:10.1016/S00068993(99)02131-9

Isola, R., Zhang, H., Tejwani, G. A., Neff, N. H., and Hadjiconstantinou, M. (2008). Dynorphin and prodynorphin mRNA changes in the striatum during nicotine withdrawal. Synapse 62, 448-455. doi:10.1002/syn. 20515

Isola, R., Zhang, H., Tejwani, G. A., Neff, N. H., and Hadjiconstantinou, M. (2009). Acute nicotine changes dynorphin and prodynorphin mRNA in the striatum. Psychopharmacology (Berl.) 201, 507-516. doi:10.1007/s00213-008-1315-4

Jackson, K. J., Carroll, F. I., Nequs, S. S., and Damaj, M. I. (2010). Effect of the selective kappa-opioid receptor antagonist JDTic on nicotine antinociception, reward, and withdrawal in the mouse. Psychopharmacology (Berl.) 210, 285-294. doi:10.1007/s00213-010-1803-1

Jackson, K. J., Martin, B. R., Changeux, J. P., and Damaj, M. I. (2008). Differential role of nicotinic acetylcholine receptor subunits in physical and affective nicotine withdrawal signs. J. Pharmacol. Exp. Ther. 325, 302-312. doi:10.1124/jpet.107.132977

Jackson, K. J., McIntosh, J. M., Brunzell, D. H., Sanjakdar, S. S., and Damaj, M. I. (2009). The role of alpha6-containing nicotinic acetylcholine receptors in nicotine reward and withdrawal. J. Pharmacol. Exp. Ther. 331, 547-554. doi:10.1124/jpet.109.155457

Jaques, J. A., Rezer, J. F., Carvalho, F. B., da Rosa, M. M., Gutierres, J. M., Gonçalves, J. F., et al. (2012). Curcumin protects against cigarette smoke-induced cognitive impairment and increased acetylcholinesterase activity in rats. Physiol. Behav. 106, 664-669. doi:10.1016/j.physbeh.2012.05.001

Johnson, P. M., Hollander, J. A., and Kenny, P. J. (2008). Decreased brain reward function during nicotine withdrawal in C57BL6 mice: evidence from intracranial self-stimulation (ICSS) studies. Pharmacol. Biochem. Behav. 90, 409-415. doi:10.1016/j.pbb

Jorenby, D. E., Steinpreis, R. E., Sherman, J. E., and Baker, T. B. (1990). Aversion instead of preference learning indicated by nicotine place conditioning in rats. Psychopharmacology (Berl.) 101, 533-538. doi:10.1007/BF02244233

Juliano, L. M., and Brandon, T. H. (2002). Effects of nicotine dose, instructional set, and outcome expectancies on the subjective effects of smoking in the presence of a stressor. J. Abnorm. Psychol. 111, 88-97. doi:10.1037/0021-843X.111.1.88

Kapelewski, C. H., Vandenbergh, D. J., and Klein, L. C. (2011) Effect of the monoamine oxidase inhibition on rewarding effects of nicotine in rodents. Curr. Drug Abuse Rev. 4, 110-121. doi:10.2174/1874473711104020110

Kenny, P. J., Chartoff, E., Roberto, M., Carlezon, W. A. Jr., and Markou, A. (2009). NMDA receptors regulate nicotine-enhanced brain reward function and intravenous nicotine self-administration: role of the ventral tegmental area and central nucleus of the amygdala. Neuropsychopharmacology 34, 266-281. doi:10.1038/npp.2008.58

Kenny, P. J., Chen, S. A., Kitamura, O., Markou, A., and Koob, G. F. (2006). Conditioned withdrawal drives heroin consumption and decreases reward sensitivity. J. Neurosci. 26, 5894-5900. doi:10.1523/JNEUROSCI.074006.2006

Kenny, P. J., and Markou, A. (2005). Conditioned nicotine withdrawal profoundly decreases the activity of brain reward systems. J. Neurosci. 25, 6208-6212. doi:10.1523/JNEUROSCI.478504.2005

Kenny, P. J., and Markou, A. (2006). Nicotine self-administration acutely activates brain reward systems and induces a long-lasting increase in reward sensitivity. Neuropsychopharmacology 31, 1203-1211.

Kenny, P. J., Paterson, N. E., Boutrel, B., Semenova, S., Harrison, A A., Gasparini, F., et al. (2003). Metabotropic glutamate 5 receptor antagonist MPEP decreased nicotine and cocaine self-administration but not nicotine and cocaineinduced facilitation of brain reward function in rats. Ann. N. Y. Acad. Sci. 1003, 415-418. doi:10.1196/annals.1300.040
Kieffer, B. L., and Evans, C. J. (2009). Opioid receptors: from binding sites to visible molecules in vivo. Opioid receptors: from binding sites to visible molecules in vivo. Neuropharmacology 56(Suppl. 1), 205-212. doi:10.1016/j.neuropharm.2008. 07.033

Kim, M. J., Fleming, C. B., and Catalano, R. F. (2009). Individual and social influences on progression to daily smoking during adolescence. Pediatrics 124, 895-902. doi:10.1542/peds.2008-2015

Koob, G. F. (1999). Stress, corticotropinreleasing factor, and drug addiction. Ann. N. Y. Acad. Sci. 897, 27-45. doi:10.1111/j.17496632.1999.tb07876.x

Koob, G. F. (2008). A role for brain stress systems in addiction. Neuron 59, 11-34. doi:10.1016/j.neuron.2008.06.012

Koob, G. F. (2010). The role of CRF and CRF-related peptides in the dark side of addiction. Brain Res. 1314, 3-14. doi:10.1016/j.brainres.2009.11. 008

Koob, G. F., Ahmed, S. H., Boutrel, B., Chen, S. A., Kenny, P. J., Markou, A., et al. (2004). Neurobiological mechanisms in the transition from drug use to drug dependence. Neurosci. Biobehav. Rev. 27, 739-749. doi:10.1016/j.neubiorev.2003.11.007

Koob, G. F., Heinrichs, S. C., Pich, E. M., Menzaghi, F., Baldwin, H., Miczek, K., et al. (1993). The role of corticotropin-releasing factor in behavioural responses to stress. Ciba Found. Symp. 172, 277-289.

Koob, G. F., and Kreek, M. J. (2007). Stress, dysregulation of drug reward pathways, and the transition to drug dependence. Am. J. Psychiatry 164, 1149-1159. doi:10.1176/appi.ajp.2007.050 30503

Koob, G. F., and Le Moal, M. (1997). Drug abuse: hedonic homeostatic dysregulation. Science 278, 52-58. doi:10.1126/science.278.5335.52

Koob, G. F., and Le Moal, M. (2001). Drug addiction, dysregulation of reward, and allostasis. Neuropsychopharmacology 24, 97-129. doi:10. 1016/S0893-133X(00)00195-0

Koob, G. F., and Le Moal, M. (2005). Plasticity of reward neurocircuitry and the 'dark side' of drug addiction. Nat. Neurosci. 8, 1442-1444. doi:10.1038/nn1105-1442

Koob, G. F., and Le Moal, M. (2008). Addiction and the brain antireward system. Annu. Rev. Psychol. 59, 29-53. doi:10.1146/annurev.psych.59.1030 06.093548 
Kosowski, A. R., Cebers, G., Cebere, A., Swanhagen, A. C., and Liljequist, S. (2004). Nicotine-induced dopamine release in the nucleus accumbens is inhibited by the novel AMPA antagonist ZK200775 and the NMDA antagonist CGP39551. Psychopharmacology (Berl.) 175, 114-123. doi:10.1007/s00213-0041797-7

Kozlowski, L. T., Mehta, N. Y., Sweeney, C. T., Schwartz, S. S., Vogler, G. P., Jarvis, M. J., et al. (1998). Filter ventilation and nicotine content of tobacco in cigarettes from Canada, the United Kingdom, and the United States. Tob. Control 7, 369-375. doi:10.1136/tc.7.4.369

Krishnan-Sarin, S., Rosen, M. I., and O’Malley, S. S. (1999). Naloxone challenge in smokers. Preliminary evidence of an opioid component in nicotine dependence. Arch. Gen. Psychiatry 56, 663-668. doi:10.1001/archpsyc.56.7.663

Lança, A. J., Adamson, K. L., Coen, K. M., Chow, B. L., and Corrigall, W. A. (2000). The pedunculopontine tegmental nucleus and the role of cholinergic neurons in nicotine self-administration in the rat: a correlative neuroanatomical and behavioral study. Neuroscience 96, 735-742. doi:10.1016/S03064522(99)00607-7

Laviolette, S. R., Alexson, T. O., and van der Kooy, D. (2002). Lesions of the tegmental pedunculopontine nucleus block the rewarding effects and reveal the aversive effects of nicotine in the ventral tegmental area. J. Neurosci. 22, 8653-8660.

Laviolette, S. R., and van der Kooy, D. (2003). The motivational valence of nicotine in the rat ventral tegmental area is switched from rewarding to aversive following blockade of the alpha7-subunit-containing nicotinic acetylcholine receptor. Psychopharmacology (Berl.) 166, 306-313.

Laviolette, S. R., and van der Kooy, D. (2004). The neurobiology of nicotine addiction: bridging the gap from molecules to behaviour. Nat. Rev. Neurosci. 5, 55-65. doi:10.1038/nrn1298

Law, M. R., Morris, J. K., and Wald, N. J. (1997). Environmental tobacco smoke exposure and ischaemic heart disease: an evaluation of the evidence. Br. Med. J. 315, 973-980. doi:10.1136/bmj.315. 7114.973

Le Foll, B., and Goldberg, S. R. (2004). Rimonabant, a CB1 antagonist, blocks nicotine-conditioned place preferences. Neuroreport 15,
2139-2143. doi:10.1097/00001756200409150-00028

Le Foll, B., and Goldberg, S. R. (2005). Nicotine induces conditioned place preferences over a large range of doses in rats. Psychopharmacology (Berl.) 178, 481-492. doi:10.1007/s00213-004-2021-5

Le Foll, B., and Goldberg, S. R. (2009). Effects of nicotine in experimental animals and humans: an update on addictive properties. Handb. Exp. Pharmacol. 192, 335-367. doi:10.1007/978-3-540-69248-5_12

Le Foll, B., Wertheim, C. E., and Goldberg, S. R. (2008). Effects of baclofen on conditioned rewarding and discriminative stimulus effects of nicotine in rats. Neurosci. Lett. 443, 236-240. doi:10.1016/j.neulet.2008.07.074

Leonardi-Bee, J., Jere, M. L., and Britton, J. (2011). Exposure to parental and sibling smoking and the risk of smoking uptake in childhood and adolescence: a systematic review and meta-analysis. Thorax 66, 847-855. doi:10.1136/thx.2010.153379

Levin, E. D., Morgan, M. M., Galvez, C., and Ellison, G. D. (1987). Chronic nicotine and withdrawal effects on body weight and food and water consumption in female rats. Physiol. Behav. 39, 441-444. doi:10.1016/0031-9384(87)90370-2

Levin, E. D., Rezvani, A. H., Montoya, D., Rose, J. E., and Swartzwelder, H. S. (2003). Adolescent-onset nicotine self-administration modeled in female rats. Psychopharmacology (Berl.) 169, 141-149. doi:10.1007/s00213-003-1486-y

Li, X., Rainnie, D. G., McCarley, R. W., and Greene, R. W. (1998). Presynaptic nicotinic receptors facilitate monoaminergic transmission. J. Neurosci. 18, 1904-1912.

Liechti, M. E., and Markou, A. (2007). Interactive effects of the mGlu5 receptor antagonist MPEP and the mGlu2/3 receptor antagonist LY341495 on nicotine self-administration and reward deficits associated with nicotine withdrawal in rats. Eur. J. Pharmacol. 554, 164-174. doi:10.1016/j.ejphar.2006.10.011

Liechti, M. E., and Markou, A. (2008). Role of the glutamatergic system in nicotine dependence: implications for the discovery and development of new pharmacological smoking cessation therapies. CNS Drugs 22, 705-724. doi:10.2165/00023210200822090-00001

Lindholm, S., Ploj, K., Franck, J., and Nylander, I. (2002). The bed nucleus is a neuroanatomical substrate for the anorectic effect of Nociceptin/orphanin FQ tissue concentration in the rat brain. Effects of repeated ethanol administration at various post-treatment intervals. Prog. Neuropsychopharmacol. Biol. Psychiatry 26, 303-306. doi:10.1016/S0278$5846(01)$

00270-6

Liu, Y., Roberts, D. C., and Morgan, D. (2005). Sensitization of the reinforcing effects of selfadministered cocaine in rats: effects of dose and intravenous injection speed. Eur. J. Neurosci. 22, 195-200. doi:10.1111/j.14609568.2005.04195.x

Lopez, M. F., and Becker, H. C. (2005). Effect of pattern and number of chronic ethanol exposures on subsequent voluntary ethanol intake in C57BL/6J mice. Psychopharmacology (Berl.) 181, 688-696. doi:10.1007/s00213-0050026-3

Lough, C., Young, T., Parker, R., Wittenauer, S., and Vincler, M. (2007). Increased spinal dynorphin contributes to chronic nicotine-induced mechanical hypersensitivity in the rat. Neurosci. Lett. 422, 54-58. doi:10.1016/j.neulet.2007.06.002

Maisonneuve, I. M., and Glick, S D. (1999). ( \pm )Cyclazocine blocks the dopamine response to nicotine. Neuroreport 10, 693-696. doi:10.1097/00001756-19990317000006

Malin, D. H. (2001). Nicotine dependence: studies with a laboratory model. Pharmacol. Biochem. Behav. 70, 551-559. doi:10.1016/S00913057(01)00699-2

Malin, D. H., and Goyarzu, P. (2009). Rodent models of nicotine withdrawal syndrome. Handb. Exp. Pharmacol. 192, 401-434. doi:10.1007/978-3-540-69248-5_14

Malin, D. H., Lake, J. R., Carter, V. A., Cunningham, J. S., and Wilson, O. B. (1993). Naloxone precipitates nicotine abstinence syndrome in the rat. Psychopharmacology (Berl.) 112, 339-342. doi:10.1007/ BF02244930

Malin, D. H., Lake, J. R., NewlinMaultsby, P., Roberts, L. K., Lanier, J. G., Carter, V. A., et al. (1992). Rodent model of nicotine abstinence syndrome. Pharmacol. Biochem. Behav. 43, 779-784. doi:10.1016/00913057(92)90408-8

Mansvelder, H. D., and McGehee, D. S. (2003). Cellular and synaptic mechanisms of nicotine addiction. J. Neurobiol. 53, 606-617. doi:10.1002/neu.10148
Mantsch, J. R., Yuferov, V., MathieuKia, A. M., Ho, A., and Kreek, M. J. (2004). Effects of extended access to high versus low cocaine doses on self-administration, cocaine-induced reinstatement and brain mRNA levels in rats. Psychopharmacology (Berl.) 175, 26-36. doi:10.1007/s00213-004-1778-x

Manzardo, A. M., Stein, L., and Belluzzi, J. D. (2002). Rats prefer cocaine over nicotine in a two-lever selfadministration choice test. Brain Res. 924, 10-19. doi:10.1016/S00068993(01)03215-2

Marchi, M., Risso, F., Viola, C., Cavazzani, P., and Raiteri, M. (2002). Direct evidencethatreleasestimulatingalpha7 ${ }^{*}$ nicotinic cholinergic receptors are localized on human and rat brain glutamatergic axon terminals. J. Neurochem. 80, 1071-1078. doi:10.1046/j.00223042.2002.00805.x

Marcinkiewcz, C. A., Prado, M. M., Isaac, S. K., Marshall, A., Rylkova, D., and Bruijnzeel, A. W. (2009). Corticotropin-releasing factor within the central nucleus of the amygdala and the nucleus accumbens shell mediates the negative affective state of nicotine withdrawal in rats. Neuropsychopharmacology 34, 1743-1752. doi:10.1038/npp.2008.231

Markou, A. (2008). Review. Neurobiology of nicotine dependence. Philos. Trans. R. Soc. Lond. $B$ Biol. Sci. 363, 3159-3168. doi:10.1098/rstb.2008.0095

Markou, A., Arroyo, M., and Everitt, B. J. (1999). Effects of contingent and non-contingent cocaine on drug-seeking behavior measured using a second-order schedule of cocaine reinforcement in rats. Neuropsychopharmacology 20, 542-555. doi:10. 1016/S0893-133X(98)00080-3

Markou, A., Kosten, T. R., and Koob, G. F. (1998). Neurobiological similarities in depression and drug dependence: a self-medication hypothesis. Neuropsychopharmacology 18, 135-174. doi:10.1016/S0893133X(97)00113-9

Markou, A., and Paterson, N. E. (2001). The nicotinic antagonist methyllycaconitine has differential effects on nicotine self-administration and nicotine withdrawal in the rat. Nicotine Tob. Res. 3, 361-373. doi:10.1080/14622200110073380

Marks, M. J., Burch, J. B., and Collins, A. C. (1983). Effects of chronic nicotine infusion on tolerance development and cholinergic receptors. J. Pharmacol. Exp. Ther. 226, 806-816. 
Marks, M. J., Pauly, J. R., Gross, S. D., Deneris, E. S., HermansBorgmeyer, I., Heinemann, S. F., et al. (1992). Nicotine binding and nicotinic receptor subunit RNA after chronic nicotine treatment. J. Neurosci. 12, 2765-2784.

Maron, D. J., and Fortmann, S. P. (1987). Nicotine yield and measures of cigarette smoke exposure in a large population: are lower-yield cigarettes safer? Am. J. Public Health 77, 546-549. doi:10.2105/AJPH.77.5.546

Martinez-Gonzalez, D., ProsperoGarcia, O., Mihailescu, S., and Drucker-Colin, R. (2002). Effects of nicotine on alcohol intake in a rat model of depression. Pharmacol. Biochem. Behav. 72, 355-364. doi:10. 1016/S0091-3057(01)00772-9

Matta, S. G., Balfour, D. J., Benowitz, N. L., Boyd, R. T., Buccafusco, J. J., Caggiula, A. R., et al. (2007). Guidelines on nicotine dose selection for in vivo research. Psychopharmacology (Berl.) 190, 269-319. doi:10.1007/s00213-0060441-0

McGehee, D. S., Heath, M. J., Gelber, S., Devay, P., and Role, L. W. (1995). Nicotine enhancement of fast excitatory synaptic transmission in CNS by presynaptic receptors. Science 269, 1692-1696. doi:10.1126/science.7569895

Meisch, R. A., and Lemaire, G. A. (1993). "Drug self-administration," in Methods in Behavioral Pharmacology, ed. F. van Harren (Amsterdam: Elsevier), 257.

Mendizábal, V., Zimmer, A., and Maldonado, R. (2006). Involvement of kappa/dynorphin system in WIN 55,212-2 self-administration in mice. Neuropsychopharmacology 31, 1957-1966. doi:10.1038/sj.npp.1300957

Merritt, L. L., Martin, B. R., Walters, C., Lichtman, A. H., and Damaj, M. I. (2008). The endogenous cannabinoid system modulates nicotine reward and dependence. J. Pharmacol. Exp. Ther. 326, 483-492. doi:10.1124/jpet.108. 138321

Mihailescu, S., Guzman-Marin, R., Dominguez, M., and Drucker-Colin, R. (2002). Mechanisms of nicotine actions on dorsal raphe serotoninergic neurons. Eur. J. Pharmacol. 452, 77-82. doi:10.1016/S00142999(02)02244-6

Mihailescu, S., Palomero-Rivero, M., Meade-Huerta, P., Maza-Flores, A., and Drucker-Colin, R. (1998). Effects of nicotine and mecamylamine on rat dorsal raphe neurons.
Eur. J. Pharmacol.360,31-36. doi:10. 1016/S0014-2999(98)00658-X

Millar, N. S., and Gotti, C. (2009). Diversity of vertebrate nicotinic acetylcholine receptors. Neuropharmacology 56, 237-246. doi:10. 1016/j.neuropharm.2008.07.041

Miyata, H., Itasaka, M., Kimura, N., and Nakayama, K. (2011). Decreases in brain reward function reflect nicotine- and methamphetaminewithdrawal aversion in rats. Curr. Neuropharmacol. 9, 63-67. doi:10.2174/157015911795017218

Nader, K., and van der Kooy, D. (1996). Clonidine antagonizes the aversive effects of opiate withdrawal and the rewarding effects of morphine only in opiate withdrawn rats. Behav. Neurosci. 110, 389-400. doi:10.1037/0735-7044.110.2.389

Natividad, L. A., Buczynski, M. W., Parsons, L. H., Torres, O. V., and O'Dell, L. E. (2012). Adolescent rats are resistant to adaptations in excitatory and inhibitory mechanisms that modulate mesolimbic dopamine during nicotine withdrawal. J. Neurochem. 123, 578-588. doi:10.1111/j.14714159.2012.07926. $\mathrm{x}$

Neal, C. R. Jr., Mansour, A., Reinscheid, R., Nothacker, H. P., Civelli, O., Akil, H., et al. (1999). Opioid receptor-like (ORL1) receptor distribution in the rat central nervous system: comparison of ORL1 receptor mRNA expression with (125)I-[(14)Tyr]-orphanin FQ binding. J. Comp. Neurol. 412, 563-605. doi:10.1002/(SICI)10969861(19991004)412:4<563::AIDCNE2>3.3.CO;2-Q

Niijima, A., Miyata, G., Sato, T., and Meguid, M. M. (2001). Hepatovagal pathway associated with nicotine's anorectic effect in the rat. Auton. Neurosci. 93, 48-55. doi:10. 1016/S1566-0702(01)00328-9

Nisell, M., Nomikos, G. G., and Svensson, T. H. (1994). Systemic nicotine-induced dopamine release in the rat nucleus accumbens is regulated by nicotinic receptors in the ventral tegmental area. Synapse 16, 36-44. doi:10.1002/syn.89016 0105

O’Byrne, K. K., Haddock, C. K., and Poston, W. S. (2002). Parenting style and adolescent smoking. J. Adolesc. Health 30, 418-425. doi:10. 1016/S1054-139X(02)00370-1

O'Connor, R. J. (2012). Non-cigarette tobacco products: what have we learnt and where are we headed? Tob. Control 21, 181-190. doi:10.1136/tobaccocontrol-2011050281
O’Dell, L. E. (2009). A psychobiological framework of the substrates that mediate nicotine use during adolescence. Neuropharmacology 56(Suppl. 1), 263-278. doi:10. 1016/j.neuropharm.2008.07.039

O’Dell, L. E., Bruijnzeel, A. W., Ghozland, S., Markou, A., and Koob, G. F. (2004). Nicotine withdrawal in adolescent and adult rats. Ann. N. Y. Acad. Sci. 1021, 167-174. doi:10.1196/annals.1308.022

O’Dell, L. E., Bruijnzeel, A. W. Smith, R. T., Parsons, L. H. Merves, M. L., Goldberger, B. A., et al. (2006). Diminished nicotine withdrawal in adolescent rats: Implications for vulnerability to addiction. Psychopharmacology (Berl.) 186, 612-619. doi:10.1007/s00213006-0383-6

O’Dell, L. E., and Koob, G. F. (2007). 'Nicotine deprivation effect' in rats with intermittent 23-hour access to intravenous nicotine self-administration. Pharmacol. Biochem. Behav. 86, 346-353. doi:10.1016/j.pbb.2007.01.004

Office of Technology Assessment. (1986). Passive Smoking in the Workplace: U.S. Congress. Washington: The Special Projects Office.

Okoli, C. T., Kelly, T., and Hahn, E. J. (2007). Secondhand smoke and nicotine exposure: a brief review. Addict. Behav. 32, 1977-1988. doi:10.1016/j.addbeh.2006.12.024

Pacifici, R., Altieri, I., Gandini, L. Lenzi, A., Passa, A. R., Pichini, S., et al. (1995). Environmental tobacco smoke: nicotine and cotinine concentration in semen. Environ. Res. 68, 69-72. doi:10.1006/enrs.1995.1009

Pandey, S. C., Zhang, H., Roy, A., and $\mathrm{Xu}, \mathrm{T}$. (2005). Deficits in amygdaloid cAMP-responsive elementbinding protein signaling play a role in genetic predisposition to anxiety and alcoholism. J. Clin. Invest. 115 2762-2773. doi:10.1172/JCI24381

Parker, L. A. (1992). Place conditioning in a three- or four-choice apparatus: role of stimulus novelty in drug-induced place conditioning. Behav. Neurosci. 106, 294-306. doi:10.1037/0735-7044.106.2.294

Parrott, A. C. (1995). Smoking cessation leads to reduced stress, but why? Int. J. Addict. 30, 1509-1516.

Parrott, A. C. (1998). Nesbitt's paradox resolved? Stress and arousal modulation during cigarette smoking. Addiction 93, 27-39. doi:10.1046/j.13600443.1998.931274.x

Parrott, A. C. (2003). Cigarettederived nicotine is not a medicine.
World J. Biol. Psychiatry 4, 49-55. doi:10.3109/15622970309167951

Paterson, D., and Nordberg, A. (2000). Neuronal nicotinic receptors in the human brain. Prog. Neurobiol. 61, 75-111. doi:10.1016/S03010082(99)00045-3

Paterson, N. E., Balfour, D. J., and Markou, A. (2008). Chronic bupropion differentially alters the reinforcing, reward-enhancing and conditioned motivational properties of nicotine in rats. Nicotine Tob. Res. 10, 995-1008. doi:10.1080/14622200802097571

Paterson, N. E., and Markou, A. (2004). Prolonged nicotine dependence associated with extended access to nicotine self-administration in rats. Psychopharmacology (Berl.) 173, 64-72. doi:10.1007/s00213-003-1692-7

Patterson, F., Benowitz, N., Shields, P., Kaufmann, V., Jepson, C., Wileyto, P., et al. (2003). Individual differences in nicotine intake per cigarette. Cancer Epidemiol. Biomarkers Prev. 12, 468-471.

Patterson, F., Lerman, C., Kaufmann, V. G., Neuner, G. A., and Audrain-McGovern, J. (2004). Cigarette smoking practices among American college students: review and future directions. $J$ Am. Coll. Health 52, 203-212. doi:10.3200/JACH.52.5.203-212

Patterson, F., Schnoll, R., Wileyto, E., Pinto, A., Epstein, L., Shields, P., et al. (2008). Toward personalized therapy for smoking cessation: a randomized placebo-controlled trial of bupropion. Clin. Pharmacol. Ther. 84, 320-325. doi:10.1038/clpt.2008.57

Pearson, J. L., Richardson, A., Niaura, R. S., Vallone, D. M., and Abrams, D. B. (2012). e-Cigarette awareness, use, and harm perceptions in US adults. Am. J. Public Health 102, 1758-1766. doi:10.2105/AJPH.2011.300526

Perkins, K. A., Briski, J., Fonte, C., Scott, J., and Lerman, C. (2009). Severity of tobacco abstinence symptoms varies by time of day. Nicotine. Tob. Res. 11, 84-91. doi:10.1093/ntr/ntn003

Perkins, K. A., and Grobe, J. E. (1992). Increased desire to smoke during acute stress. Br. J. Addict. 87, 1037-1040. doi:10.1111/j.13600443.1992.tb03121.x

Perkins, K. A., Sexton, J. E., Reynolds, W. A., Grobe, J. E., Fonte, C., and Stiller, R. L. (1994). Comparison of acute subjective and heart rate effects of nicotine intake via tobacco smoking versus nasal spray. Pharmacol. Biochem. Behav. 47, 295-299. doi:10.1016/00913057(94)90013-2 
Peyron, C., Tighe, D. K., van den Pol, A. N., de Lecea, L., Heller, H. C., Sutcliffe, J. G., et al. (1998). Neurons containing hypocretin (orexin) project to multiple neuronal systems. J. Neurosci. 18, 9996-10015.

Picciotto, M. R., Addy, N. A., Mineur, Y. S., and Brunzell, D. H. (2008). It is not "either/or": activation and desensitization of nicotinic acetylcholine receptors both contribute to behaviors related to nicotine addiction and mood. Prog. Neurobiol. 84, 329-342. doi:10.1016/j.pneurobio.2007.12.005

Picciotto, M. R., and Corrigall, W. A. (2002). Neuronal systems underlying behaviors related to nicotine addiction: neural circuits and molecular genetics. J. Neurosci. 22, 3338-3341.

Picciotto, M. R., Zoli, M., Rimondini, R., Léna, C., Marubio, L. M., Pich, E. M., et al. (1988). Acetylcholine receptors containing the beta2 subunit are involved in the reinforcing properties of nicotine. Nature 391, 173-177.

Plaza-Zabala, A., Flores, Á., Maldonado, R., and Berrendero, F. (2012). Hypocretin/orexin signaling in the hypothalamic paraventricular nucleus is essential for the expression of nicotine withdrawal. Biol. Psychiatry 71, 214-223. doi:10.1016/j.biopsych.2011.06.025

Plowchalk, D. R., Andersen, M. E., and deBethizy, J. D. (1992). A physiologically based pharmacokinetic model for nicotine disposition in the Sprague-Dawley rat. Toxicol. Appl. Pharmacol. 116, 177-188. doi:10.1016/0041-008X(92)90297-6

Polosa, R., Caponnetto, P., Morjaria, J. B., Papale, G., Campagna, D., and Russo, C. (2011). Effect of an electronic nicotine delivery device (e-Cigarette) on smoking reduction and cessation: a prospective 6-month pilot study. BMC Public Health 11:786. doi:10.1186/14712458-11-786

Pomerleau, C. S., and Pomerleau, O. F. (1992). Euphoriant effects of nicotine in smokers. Psychopharmacology (Berl.) 108, 460-465. doi:10.1007/BF02247422

Pomerleau, O. F., Turk, D. C., and Fertig, J. B. (1984). The effects of cigarette smoking on pain and anxiety. Addict. Behav. 9, 265-271. doi:10.1016/0306-4603(84)90018-2

Pontieri, F. E., Tanda, G., Orzi, F., and Di Chiara, G. (1996). Effects of nicotine on the nucleus accumbens and similarity to those of addictive drugs. Nature 382, 255-257. doi: $10.1038 / 382255 \mathrm{a} 0$
Prochazka, A. V., Petty, T. L., Nett, L., Silvers, G. W., Sachs, D. P., Rennard, S. I., et al. (1992). Transdermal clonidine reduced some withdrawal symptoms but did not increase smoking cessation. Arch. Intern. Med. 152, 2065-2069. doi:10.1001/archinte.1992.0040022 0083015

Reinscheid, R. K., Nothacker, H. P., Bourson, A., Ardati, A., Henningsen, R. A., Bunzow, J. R., et al. (1995). Orphanin FQ: a neuropeptide that activates an opioid like $G$ protein-coupled receptor. Science 270, 792-794. doi:10.1126/science.270.5237.792

Ribeiro, E. B., Bettiker, R. L., Bogdanov, M., and Wurtman, R. J. (1993). Effects of systemic nicotine on serotonin release in rat brain. Brain Res. 621, 311-318. doi:10.1016/0006-8993(93)90121-3

Risner, M. E., and Goldberg, S. R. (1983). A comparison of nicotine and cocaine self-administration in the dog: fixed-ratio and progressiveratio schedules of intravenous drug infusion. J. Pharmacol. Exp. Ther. 224, 319-326.

Robinson, L. A., Vander Weg, M. W., Riedel, B. W., Klesges, R. C., and McLain-Allen, B. (2003). Start to stop: results of a randomized controlled trial of a smoking cessation program for teens. Tob. Control 12(Suppl. 4), iv26-iv33. doi:10.1136/tc.12.suppl_4.iv26

Rose, J. E. (2006). Nicotine and nonnicotine factors in cigarette addiction. Psychopharmacology (Berl.) 184, 274-285. doi:10.1007/s00213005-0250- $\mathrm{x}$

Rose, J. E., and Corrigall, W. A. (1997). Nicotine self-administration in animals and humans: similarities and differences. Psychopharmacology (Berl.) 130, 28-40. doi:10.1007/s002130050209

Rose, J. E., Salley, A., Behm, F. M., Bates, J. E., and Westman, E. C. (2010). Reinforcing effects of nicotine and non-nicotine components of cigarette smoke. Psychopharmacology (Berl.) 210, 1-12. doi:10.1007/s00213-010-1810-2

Rosecrans, J. A., and Meltzer, L. T. (1981). Central sites and mechanisms of action of nicotine. Neurosci. Biobehav. Rev. 5, 497-501. doi:10.1016/0149-7634(81)90020-8

Roth-Deri, I., Green-Sadan, T., and Yadid, G. (2008). Beta-endorphin and drug-induced reward and reinforcement. Prog. Neurobiol. 86, 1-21. doi:10.1016/j.pneurobio.2008.06.003 Russell, M. A., Jarvis, M., Iyer, R., and Feyerabend, C. (1980). Relation of nicotine yield of cigarettes to blood nicotine concentrations in smokers. Br. Med. J. 280, 972-976. doi:10.1136/bmj.280.6219.972

Rylkova, D., Boissoneault, J., Isaac, S., Prado, M., Shah, H. P., and Bruijnzeel, A. W. (2008). Effects of NPY and the specific Y1 receptor agonist [D-His(26)]-NPY on the deficit in brain reward function and somatic signs associated with nicotine withdrawal in rats. Neuropeptides 42, 215-227. doi:10.1016/j.npep.2008.03.004

Sahley, T. L., and Berntson, G. G. (1979). Antinociceptive effects of central and systemic administrations of nicotine in the rat. Psychopharmacology (Berl.) 65, 279-283. doi:10.1007/BF00492216

Sajdyk, T. J., Vandergriff, M. G., and Gehlert, D. R. (1999). Amygdalar neuropeptide Y Y1 receptors mediate the anxiolytic-like actions of neuropeptide $\mathrm{Y}$ in the social interaction test. Eur. J. Pharmacol. 368, 143-147. doi:10.1016/S00142999(99)00018-7

Sakamoto, F., Yamada, S., and Ueta, Y. (2004). Centrally administered orexin-A activates corticotropinreleasing factor-containing neurons in the hypothalamic paraventricular nucleus and central amygdaloid nucleus of rats: possible involvement of central orexins on stress-activated central CRF neurons. Regul. Pept. 118, 183-191. doi:10.1016/j.regpep.2003. 12.014

Sakoori, K., and Murphy, N. P. (2009). Enhanced nicotine sensitivity in nociceptin/orphanin FQ receptor knockout mice. Neuropharmacology 56, 896-904. doi:10. 1016/j.neuropharm.2009.01.016

Sakurai, T., Nagata, R., Yamanaka, A., Kawamura, H., Tsujino, N., Muraki, Y., et al. (2005). Input of orexin/hypocretin neurons revealed by a genetically encoded tracer in mice. Neuron 46, 297-308. doi:10.1016/j.neuron.2005.03.010

Schmidt, B. L., Tambeli, C. H., Gear, R. W., and Levine, J. D. (2001). Nicotine withdrawal hyperalgesia and opioid-mediated analgesia depend on nicotine receptors in nucleus accumbens. Neuroscience 106, 129-136. doi:10.1016/S03064522(01)00264-0

Schoepp, D. D., Wright, R. A., Levine, L. R., Gaydos, B., and Potter, W. Z. (2003). LY354740, an mGlu2/3 receptor agonist as a novel approach to treat anxiety/stress. Stress 6, 189-197. doi:10.1080/1025389031000146773
Semenova, S., and Markou, A. (2010). The alpha2 adrenergic receptor antagonist idazoxan, but not the serotonin-2A receptor antagonist M100907, partially attenuated reward deficits associated with nicotine, but not amphetamine, withdrawal in rats. Eur. Neuropsychopharmacol. 20, 731-746. doi:10.1016/j.euroneuro.2010.05.003

Shiffman, S. (1989). Tobacco bchippersQ - individual differences in tobacco dependence. Psychopharmacology (Berl.) 97, 539-547. doi:10.1007/BF00439561

Shiffman, S., Paty, J. A., Kassel, J. D., Gnys, M., and Zettler-Segal, M. (1994). Smoking behavior and smoking history of tobacco chippers. Exp. Clin. Psychopharmacol. 2, 126-142. doi:10.1037/10641297.2.2.126

Shippenberg, T. S., Zapata, A., and Chefer, V. I. (2007). Dynorphin and the pathophysiology of drug addiction. Pharmacol. Ther. 116, 306-321. doi:10.1016/j.pharmthera.2007. 06.011

Shoaib, M., Schindler, C. W., and Goldberg, S. R. (1997). Nicotine self-administration in rats: strain and nicotine preexposure effects on acquisition. Psychopharmacology (Berl.) 129, 35-43. doi:10.1007/s002130050159

Shram, M. J., Funk, D., Li, Z., and Le, A. D. (2006). Periadolescent and adult rats respond differently in tests measuring the rewarding and aversive effects of nicotine. Psychopharmacology (Berl.) 186, 201-208. doi:10.1007/s00213-006-0373-8

Shram, M. J., Siu, E. C., Li, Z., Tyndale, R. F., and Lê, A. D. (2008). Interactions between age and the aversive effects of nicotine withdrawal under mecamylamine-precipitated and spontaneous conditions in male Wistar rats. Psychopharmacology (Berl.) 198, 181-190. doi:10.1007/s00213-008-1115-x

Siegel, M. B., Tanwar, K. L., and Wood, K. S. (2011). Electronic cigarettes as a smoking-cessation: tool results from an online survey. Am. J. Prev. Med. 40, 472-475. doi:10.1016/j.amepre.2010.12.006

Simons, C. T., Cuellar, J. M., Moore, J. A., Pinkerton, K. E., Uyeminami, D., Carstens, M. I., et al. (2005). Nicotinic receptor involvement in antinociception induced by exposure to cigarette smoke. Neurosci. Lett. 389, 71-76. doi:10.1016/j.neulet.2005.07.025

Sinclair, J. D., and Senter, R. J. (1967). Increased preference for ethanol in rats following alcohol 
deprivation. Psychonom. Sci. 8, 11-12.

Slawecki, C. J., Gilder, A., Roth, J., and Ehlers, C. L. (2003). Increased anxiety-like behavior in adult rats exposed to nicotine as adolescents. Pharmacol. Biochem. Behav. 75, 355-361. doi:10.1016/S00913057(03)00093-5

Slawecki, C. J., Thorsell, A. K., Khoury, A. E., Mathe, A. A., and Ehlers, C. L. (2005). Increased CRF-like and NPY-like immunoreactivity in adult rats exposed to nicotine during adolescence: relation to anxietylike and depressive-like behavior. Neuropeptides 39, 369-377. doi:10.1016/j.npep.2005.06.002

Slotkin, T. A., Pinkerton, K. E., and Seidler, F. J. (2006). Perinatal environmental tobacco smoke exposure in rhesus monkeys: critical periods and regional selectivity for effects on brain cell development and lipid peroxidation. Environ. Health Perspect. 114, 34-39.

Small, E., Shah, H. P., Davenport, J. J., Geier, J. E., Yamada, H., Sabarinath, S. N., et al. (2010). Tobacco smoke exposure induces nicotine dependence in rats. Psychopharmacology (Berl.) 208, 143-158. doi:10.1007/s00213-009-1716-z

Smith, R. J., and Aston-Jones, G. (2008). Noradrenergic transmission in the extended amygdala: role in increased drug-seeking and relapse during protracted drug abstinence. Brain Struct. Funct. 213, 43-61. doi:10.1007/s00429-008-0191-3

Sofuoglu, M., Yoo, S., Hill, K. P., and Mooney, M. (2008). Selfadministration of intravenous nicotine in male and female cigarette smokers. Neuropsychopharmacology 33, 715-720. doi:10.1038/sj.npp.1301460

Solomon, R. L., and Corbit, J. D. (1973). An opponent-process theory of motivation: II. Cigarette addiction. J. Abnorm. Psychol. 81, 158-171. doi:10.1037/h0034534

Sorge, R. E., and Clarke, P. B. (2009). Rats self-administer intravenous nicotine delivered in a novel smoking-relevant procedure: effects of dopamine antagonists. J. Pharmacol. Exp. Ther. 330, 633-640. doi:10.1124/jpet.109.154641

Specio, S. E., Wee, S., O'Dell, L. E., Boutrel, B., Zorrilla, E. P., and Koob, G. F. (2008). CRF1 receptor antagonists attenuate escalated cocaine selfadministration in rats. Psychopharmacology (Berl.) 196, 473-482. doi:10.1007/s00213-007-0983-9

Sperling, R., and Commons, K. G. (2011). Shifting topographic activation and 5-HT1A receptormediated inhibition of dorsal raphe serotonin neurons produced by nicotine exposure and withdrawal. Eur. J. Neurosci. 33, 1866-1875. doi:10.1111/j.14609568.2011.07677.x

Spiller, K., Xi, Z. X., Li, X., Ashby, C. R., Callahan, P. M., Tehim, A., et al. (2009). Varenicline attenuates nicotine-enhanced brain-stimulation reward by activation of alpha4beta2 nicotinic receptors in rats. Neuropharmacology 57, 60-66. doi:10. 1016/j.neuropharm.2009.04.006

Steinbusch, H. (1984). "Serotoninimmunoreactive neurons and their projections in the CNS," in Handbook of Chemical Neuroanatomy, eds A. Bjorklund, T. Hokfelt, and M. Kuhar (Amsterdam: Elsevier Science Publishers), 68-121.

Stoker, A. K., Olivier, B., and Markou, A. (2012). Involvement of metabotropic glutamate receptor 5 in brain reward deficits associated with cocaine and nicotine withdrawal and somatic signs of nicotine withdrawal. Psychopharmacology (Berl.) 221, 317-327. doi:10.1007/s00213-011-2578-8

Stoker, A. K., Semenova, S., and Markou, A. (2008). Affective and somatic aspects of spontaneous and precipitated nicotine withdrawal in $\mathrm{C} 57 \mathrm{BL} / 6 \mathrm{~J}$ and $\mathrm{BALB} / \mathrm{cByJ}$ mice. Neuropharmacology 54, 1223-1232. doi:10.1016/j.neuropharm.2008. 03.013

Stolerman, I. P., and Jarvis, M. J. (1995). The scientific case that nicotine is addictive. Psychopharmacology (Berl.) 117, 2-10; discussion, 14-20.

Substance Abuse and Mental Health Services Administration. (2003). Results from the 2002 National Survey on Drug Use and Health: National Findings. Rockville: U.S. Office of Applied Studies.

Suemaru, K., Oishi, R., Gomita, Y., Saeki, K., and Araki, Y. (1992). Effect of long-term cigarette smoke exposure on locomotor activity and brain monoamine levels in rats. Pharmacol. Biochem. Behav. 41, 655-658. doi:10.1016/0091-3057(92)90388-V

Sutcliffe, J. G., and de Lecea, L. (2002). The hypocretins: setting the arousal threshold. Nat. Rev. Neurosci. 3, 339-349. doi:10.1038/nrn808

Sutherland, G., Stapleton, J. A., Russell, M. A., and Feyerabend, C. (1995). Naltrexone, smoking behaviour and cigarette withdrawal. Psychopharmacology (Berl.) 120, 418-425. doi:10.1007/BF02245813
Suzuki, R., Lumeng, L., McBride, W. J., Li, T. K., and Hwang, B. H. (2004). Reduced neuropeptide Y mRNA expression in the central nucleus of amygdala of alcohol preferring $(\mathrm{P})$ rats: its potential involvement in alcohol preference and anxiety. Brain Res. 1014, 251-254. doi:10.1016/j.brainres.2004.04.037

Suzuki, T., Ise, Y., Mori, T., and Misawa, M. (1997). Attenuation of mecamylamine-precipitated nicotine-withdrawal aversion by the 5-HT3 receptor antagonist ondansetron. Life Sci. 61, L249-254. doi:10. 1016/S0024-3205(97)00745-5

Suzuki, T., Ise, Y., Tsuda, M., Maeda, J., and Misawa, M. (1996). Mecamylamine-precipitated nicotine-withdrawal aversion in rats. Eur. J. Pharmacol. 314, 281-284. doi:10.1016/S00142999(96)00723-6

Taheri, S., Zeitzer, J. M., and Mignot, E. (2002). The role of hypocretins (orexins) in sleep regulation and narcolepsy. Annu. Rev. Neurosci. 25, 283-313. doi:10.1146/annurev.neuro.25.112 701.142826

Thorsell, A., Repunte-Canonigo, V., O’Dell, L. E., Chen, S. A., King, A. R., Lekic, D., et al. (2007). Viral vector-induced amygdala NPY over expression reverses increased alcohol intake caused by repeated deprivations in Wistar rats. Brain 130, 1330-1337. doi:10.1093/brain/awm033

Torres, O. V., Tejeda, H. A., Natividad, L. A., and O'Dell, L. E. (2008). Enhanced vulnerability to the rewarding effects of nicotine during the adolescent period of development. Pharmacol. Biochem. Behav. 90, 658-663. doi:10.1016/j.pbb.2008.05.009

Tovote, P., Meyer, M., Beck-Sickinger, A. G., von Hörsten, S., Ove Ogren, S., Spiess, J., et al. (2004). Central NPY receptor-mediated alteration of heart rate dynamics in mice during expression of fear conditioned to an auditory cue. Regul. Pept. 120 205-214. doi:10.1016/j.regpep.2004. 03.011

Trigo, J. M., Zimmer, A., and Maldonado, R. (2009). Nicotine anxiogenic and rewarding effects are decreased in mice lacking beta-endorphin. Neuropharmacology 56, 1147-1153. doi:10.1016/j.neuropharm.2009.03. 013

Tucci, S., Cheeta, S., Seth, P., and File, S. E. (2003). Corticotropin releasing factor antagonist, -helical CRF9-41, reverses nicotine-induced conditioned, but not unconditioned, anxiety. Psychopharmacology (Berl.) 167, 251-256.

Tucker, J. S., Ellickson, P. L., and Klein, D. J. (2003). Predictors of the transition to regular smoking during adolescence and young adulthood. J. Adolesc. Health 32, 314-324. doi:10.1016/ S1054-139X(02)00709-7

Turner, J. A., McNicol, M. W., and Sillett, R. W. (1986). Distribution of carboxyhaemoglobin concentrations in smokers and non-smokers. Thorax 41, 25-27.

U.S. Department of Health and Human Services. (1994). Preventing Tobacco Use Among Youth and Young Adults: A Report of the Surgeon General. Atlanta, GA: Centers for Disease Control and Prevention, Office on Smoking and Health.

U.S. Department of Health and Human Services. (2006). The Health Consequences of Involuntary Exposure to Tobacco Smoke: A Report of the Surgeon General. Atlanta, GA: Centers for Disease Control and Prevention, Office on Smoking and Health.

U.S. Department of Health and Human Services. (2012). Preventing Tobacco Use Among Young People: A Report of the Surgeon General. Atlanta, GA: Centers for Disease Control and Prevention, Office on Smoking and Health.

Valdez, G. R., Inoue, K., Koob, G. F., Rivier, J., Vale, W. W., and Zorrilla, E. P. (2002). Human urocortin II: mild locomotor suppressive and delayed anxiolytic-like effects of a novel corticotropin-releasing factor related peptide. Brain Res 943, 142-150. doi:10.1016/S00068993(02)02707-5

Valdez, G. R., Zorrilla, E. P., Rivier, J., Vale, W. W., and Koob, G. F. (2003). Locomotor suppressive and anxiolytic-like effects of urocortin 3, a highly selective type 2 corticotropin-releasing factor agonist. Brain Res. 980, 206-212. doi:10. 1016/S0006-8993(03)02971-8

Vale, W., Rivier, C., Brown, M. R., Spiess, J., Koob, G., Swanson, L., et al. (1983). Chemical and biological characterization of corticotropin releasing factor. Recent Prog. Horm. Res. 39, 245-270.

Vale, W., Spiess, J., Rivier, C., and Rivier, J. (1981). Characterization of a 41-residue ovine hypothalamic peptide that stimulates secretion of corticotropin and betaendorphin. Science 213, 1394-1397. doi:10.1126/science.6267699

Valentine, J. D., Hokanson, J. S., Matta, S. G., and Sharp, B. M. 
(1997). Self-administration in rats allowed unlimited access to nicotine. Psychopharmacology (Berl.) 133, 300-304. doi:10.1007/s002130050405

Vansickel, A. R., Cobb, C. O., Weaver, M. F., and Eissenberg, T. E. (2010). A clinical laboratory model for evaluating the acute effects of electronic "cigarettes": nicotine delivery profile and cardiovascular and subjective effects. Cancer Epidemiol. Biomarkers Prev. 19, 1945-1953. doi:10.1158/10559965.EPI-10-0288

Vansickel, A. R., and Eissenberg, T. (2013). Electronic cigarettes: effective nicotine delivery after acute administration. Nicotine Tob. Res. 15, 267-270. doi:10.1093/ntr/ntr316

Vendruscolo, L. F., Barbier, E., Schlosburg, J. E., Misra, K. K., Whitfield, T. W., Logrip, M. L., et al. (2012). Corticosteroiddependent plasticity mediates compulsive alcohol drinking in rats. J. Neurosci. 32, 7563-7571. doi:10.1523/JNEUROSCI.006912.2012

Vlachou, P. A., Khalili, K., Jang, H. J., Fischer, S., Hirschfield, G. M., and Kim, T. K. (2011). IgG4-related sclerosing disease: autoimmune pancreatitis and extrapancreatic manifestations. Radiographics 31, 1379-1402. doi:10.1148/rg.315105735

Wagener, T. L., Siegel, M., and Borrelli, B. (2012). Electronic cigarettes: achieving a balanced perspective. Addiction 107, 1545-1548. doi:10.1111/j.13600443.2012.03826.x

Wakabayashi, K. T., Weiss, M. J., Pickup, K. N., and Robinson, T. E. (2010). Rats markedly escalate their intake and show a persistent susceptibility to reinstatement only when cocaine is injected rapidly. J. Neurosci. 30, 11346-11355. doi:10.1523/JNEUROSCI.252410.2010
Wang, M. P., Ho, S. Y., and Lam, T. H. (2011). Parental smoking, exposure to secondhand smoke at home, and smoking initiation among young children. Nicotine Tob. Res. 13, 827-832. doi:10.1093/ntr/ntr083

Watkins, S. S., Epping-Jordan, M. P., Koob, G. F., and Markou, A. (1999). Blockade of nicotine self-administration with nicotinic antagonists in rats. Pharmacol. Biochem. Behav. 62, 743-751. doi:10. 1016/S0091-3057(98)00226-3

Watkins, S. S., Stinus, L., Koob, G. F., and Markou, A. (2000a). Reward and somatic changes during precipitated nicotine withdrawal in rats: centrally and peripherally mediated effects. J. Pharmacol. Exp. Ther. 292, 1053-1064.

Watkins, S. S., Koob, G. F., and Markou, A. (2000b). Neural mechanisms underlying nicotine addiction: acute positive reinforcement and withdrawal. Nicotine Tob. Res. 2, 19-37. doi:10.1080/146222000500 11277

West, R., Hajek, P., and McNeill, A. (1991). Effect of buspirone on cigarette withdrawal symptoms and short-term abstinence rates in a smokers clinic. Psychopharmacology (Berl.) 104, 91-96. doi:10.1007/BF02244560

Wilkie, G. I., Hutson, P. H., Stephens, M. W., Whiting, P., and Wonnacott, S. (1993). Hippocampal nicotinic autoreceptors modulate acetylcholine release. Biochem. Soc. Trans. 21, 429-431.

Wilmouth, C. E., and Spear, L. P. (2006). Withdrawal from chronic nicotine in adolescent and adult rats. Psychol. Addict. Behav. 21, 127-137.

Winsky-Sommerer, R., Yamanaka, A., Diano, S., Borok, E., Roberts, A. J., Sakurai, T., et al. (2004). Interaction between the corticotropinreleasing factor system and hypocretins (orexins): a novel circuit mediating stress response. J. Neurosci. 24, 11439-11448. doi:10.1523/JNEUROSCI.345904.2004

Wooltorton, J. R., Pidoplichko, V. I., Broide, R. S., and Dani, J. A. (2003). Differential desensitization and distribution of nicotinic acetylcholine receptor subtypes in midbrain dopamine areas. J. Neurosci. 23, 3176-3185.

Yamada, H., Bishnoi, M., Keijzers, K. F. van Tuijl, I. A., Small, E., Shah, H. P., et al. (2010). Preadolescent tobacco smoke exposure leads to acute nicotine dependence but does not affect the rewarding effects of nicotine or nicotine withdrawal in adulthood in rats. Pharmacol. Biochem. Behav. 95, 401-409. doi:10.1016/j.pbb.2010.02. 018

Yang, C. Y., Wu, W. H., and Zbuzek, V. K. (1992). Antinociceptive effect of chronic nicotine and nociceptive effect of its withdrawal measured by hot-plate and tail-flick in rats. Psychopharmacology (Berl.) 106, 417-420. doi:10.1007/BF022 45428

Yang, X., Criswell, H. E., and Breese, G. R. (1996). Nicotine-induced inhibition in medial septum involves activation of presynaptic nicotinic cholinergic receptors on gammaaminobutyric acid-containing neurons. J. Pharmacol. Exp. Ther. 276, 482-489.

Yee, B. E., Ahmed, M. I., Brugge, D. Farrell, M., Lozada, G., Idupaganthi, R., et al. (2010). Second-hand smoking and carboxyhemoglobin levels in children: a prospective observational study. Paediatr. Anaesth. 20, 82-89. doi:10.1111/j.14609592.2009.03192.x

Young, S. N., Smith, S. E., Pihl, R. O., and Ervin, F. R. (1985). Tryptophan depletion causes a rapid lowering of mood in normal males. Psychopharmacology (Berl.) 87, 173-177. doi:10.1007/BF00431803
Zaniewska, M., Przegalinski, E., and Filip, M. (2009). Nicotine dependence - human and animal studies, current pharmacotherapies and future perspectives. Pharmacol. Rep. 61, 957-965.

Zhan, W., Dierker, L. C., Rose, J. S., Selya, A., and Mermelstein, R. J. (2012). The natural course of nicotine dependence symptoms among adolescent smokers. Nicotine Tob. Res. 14, 1445-1452. doi:10.1093/ntr/nts031

Zorrilla, E. P., Valdez, G. R., Nozulak, J., Koob, G. F., and Markou, A. (2002). Effects of antalarmin, a CRF type 1 receptor antagonist, on anxiety-like behavior and motor activation in the rat. Brain Res. 952, 188-199. doi:10.1016/S00068993(02)03189-X

Conflict of Interest Statement: The authors declare that the research was conducted in the absence of any commercial or financial relationships that could be construed as a potential conflict of interest.

Received: 26 February 2013; accepted: 13 May 2013; published online: 04 June 2013.

Citation: Cohen A and George O (2013) Animal models of nicotine exposure: relevance to second-hand smoking, electronic cigarette use, and compulsive smoking. Front. Psychiatry 4:41. doi: 10.3389/fpsyt.2013.00041

This article was submitted to Frontiers in Addictive Disorders and Behavioral Dyscontrol, a specialty of Frontiers in Psychiatry.

Copyright (c) 2013 Cohen and George. This is an open-access article distributed under the terms of the Creative Commons Attribution License, which permits use, distribution and reproduction in other forums, provided the original authors and source are credited and subject to any copyright notices concerning any third-party graphics etc. 